\title{
Del gran abaratamiento a la gran implosión. Clase, clima y la Gran Frontera
}

\author{
JASON W. MOORE*
}

\section{RESUMEN}

Este artículo vincula dos grandes acontecimientos histórico-mundiales: el auge del capitalismo tras 1492 y su crisis epocal actual, al final del Holoceno. El autor sostiene que la interminable acumulación de capital ha sido, desde el principio, posibilitada por la interminable conquista de la Tierra: la Gran Frontera. La ecología-mundo capitalista es un tipo peculiar de sociedad de clases que combina la acumulación monetaria con la apropiación excepcionalmente rápida del trabajo humano y planetario. La Gran Frontera es la zona de la Naturaleza Barata, uniendo dialéctica-mente la valorización del capital y la desvalorización ético-política de los humanos y del resto de la naturaleza, así, el racismo, el sexismo y el prometeísmo revelan ser pilares ideológicos fundamentales de la acumulación de capital. De manera crucial, la Gran Frontera ha permitido a las burguesías imperialistas avanzar en la productividad del trabajo, reducir los costes de los insumos y resolver las recurrentes crisis de sobreacumulación del capitalismo. Hoy en día, estamos asistiendo a la inversión geohistórica de la estrategia de la Naturaleza Barata del capitalismo. Se trata de la transición de la red de la vida como una dinámica de reducción de costes y aumento de la productividad a otra de maximización de costes y reducción de la productividad. La clase dominante y los economistas marxistas han entendido sus primeros signos como el "Gran Estancamiento". Pero esto es sólo el principio; podríamos llamarlo una “crisis de señalización”. El Gran Estancamiento indica los primeros momentos de la Gran Implosión. Al igual que el cambio climático se entiende como un proceso no lineal que confunde los modelos biosféricos, la Gran Implosión es una dinámica no lineal a través de la cual las contradicciones del capitalismo en la red de la vida confunden los modelos lineales del cambio histórico. El capitalismo, frente a este panorama, es mucho más vulnerable de lo que creemos, y, sobre todo, lo es a la revuelta que el Proletariado Planetario está cociendo a fuego lento.

\section{Palabras Clave}

Ecología-mundo; historia del clima; capitalismo; economía política; ecología política; desarrollo sostenible.

\section{TITLE}

From the great cheapening to the great implosion. Class, climate and the Great Frontier

\section{Extended Abstract}

This article reconceptualizes the history of the capitalist world-ecology through the enclosure of the Great Frontier. Conceptualizing capitalism as a world-ecology of power, profit and life, the author argues that the underlying source of capitalism's success has been its capacity to "put nature to work" - as cheaply as possible. This Cheap Nature strategy combines capitalization (the logic of capital) with extra-economic appropriation, including the socially-necessary unpaid work of humans.At the core of every great wave of capitalist development has been the Four Cheaps: labor, food, energy, and raw materials. Those Cheap Natures were appropriated - through the dynamics of imperialism and militarized accumulation through great waves of planetary enclosure, what I call the Great Frontier.These enclosures allowed imperial bourgeoisies to win the worldwide class struggle; to reduce the costs of production and therefore to advance the rate of profit; to resolve the surplus capital problem; and to sustain labor productivity growth. Today, the continuation of these four great bourgeois accomplishments are in question.

The climate crisis represents the biospheric contradiction of the worldwide class struggle in the web of life. The en-closure of the atmospheric commons is a pivotal moment in the epochal crisis of capitalism - understood through the dialectic of

DOI:

https://doi.org/I0.I5366/relacionesinternacionales202I.47.00 I

Formato de citación recomendado:

MOORE, Jason W. (202I). “Del gran abaratamiento a la gran implosión. Clase, clima y la Gran Frontera”, Relaciones Internacionales, $\mathrm{n}^{\circ} 47$, pp. II-52.
* Jason W. MOORE,

Enseña historia del mundo y ecologíamundo y pertenece al World-Ecology Research Group en la Universidad de Binghamton (Estados Unidos), donde es profesor de sociología. Entre sus libros figuran "Capitalism in the Web of Life: Ecology and the Accumulation of Capital" (20I5) y

"A History of the World in Seven Cheap Things" (2017), escrito junto con Raj Patel. Muchos de sus ensayos, incluidas las traducciones, pueden consultarse en su sitio web. Escribe regularmente en su blog: https:// jasonwmoore. wordpress. com/ Contacto: jwmoore@ binghamton.edu

Traducción: Yoan MOLINEROGERBEAU 
planetary life and world accumulation. The more that capital and the imperialist forces seek to sub-ordinate the biosphere to the logic of endless accumulation, the more that webs of life find creative and non-linear ways to defy and resist the planetary dictatorship of capital.

This dialectic prefigures the Great Implosion. The Great Implosion thesis contends that the dynamics of non-linear change attributed to the climate crisis apply also to capitalism's unfolding epochal crisis. The geohistorical transition now underway is an epochal inversion of capitalism's defining relation with and within the web of life. This is the transition from the web of life as a cost-reducing and productivity-advancing dynamic to a cost-maximizing and productivity-reducing one. Its early signs are now widely grasped as the Great Stagnation. But this is only the beginning; we might call it a signaling crisis. The Great Stagnation signals the first moments of the Great Implosion.

The author constructs the rise and ongoing demise of the Great Frontier in three parts, focusing successively on environmental history, Civilizing Projects, and today's climate crisis. In Part I, I reprise the historical-geographical outlines of the Great Frontier in the rise of capitalism. The author revisits core elements of the commodity frontier argument, developed to interpret the epochal shift in world environmental history after 1492

From this historical-geographical sketch of the rise of capitalism, I unpack a twofold argument. One is that com-modity frontiers are not strictly about commodities or commodification. They are about imperialism, which is always the world bourgeoisie's favored mode of class formation. Imperialism is the world politics of the tendency (and countertendency) of the rate of profit to fall. It is premised not only on armed force but also on the geocultural hegemony and violence of Civilizing Projects. This is the focus of Part II.To be sure, commodification is in play; but to reduce the story to market forces replays a neo-Smithian error. It fails to grasp the centrality of imperialism and its mechanisms of class power in forging capitalism's major commodity frontiers. Capitalist relations of Nature - I use the uppercase to underscore the real abstraction - are always politically-mediated by states that pursue the creation and reproduction of a "good business environment."The (geo)political project of managing and securing webs of life for capital depends upon a geocultural project that makes possible the practical violence of commodity fetishism on the Great Frontier. This is civilizational fetishism. Its expressions are found the successive and over-lapping Christianizing, Civilizing, and Developmentalist Projects of great empires, given intellectual expression over the longue durée by figures ranging from Francisco deVitoria to WaltW. Rostow. These projects reproduce and reinvent the ruling abstractions of Civilization and Savagery. After 1949, this was President Truman's "Point Four" declaration on the divide between the "developed" and "undeveloped world."

A second argument foregrounds the connective tissues binding our historical-geographical assessments of capitalist frontiermaking and today's climate crisis. In Part III, I frame the planetary crisis as joining two fundamental mo-ments: an unfolding crisis in life-making, registered widely in the climate and biodiversity literatures; and an unfold-ing crisis in profit-making, registered widely in the Great Stagnation discourse. Those two moments are unevenly combined in the geohistorical character of climate crisis, one in which the geophysical turning point finds expression in the destabilization of a trinity born in the seventeenth century: the climate class divide, climate patriarchy, cli-mate apartheid. The seventeenth-century's climate crisis hothoused the Great Frontier as accumulation strategy, assuming its modern form between I550 and 1700 as a climate fix to the era's "general crisis": an era of intermi-nable war, endemic political crisis, and economic instability. In this era we find the maturation of capitalism's Plane-tary Proletariat, joining socially necessary "paid" and "unpaid" work by humans and the rest of nature: the differen-tiated unity of Proletariat, Femitariat, and Biotariat

The blossoming of the Great Frontier as a full-fledged productivist revolution — the Plantation Revolution — inaugu-rated the Great Cheapening, a long-run secular decline in the price (value composition) of the Big Four inputs: la-bor-power, food, energy, and raw materials. A specifically capitalist historical nature was born, and its epoch-making service to world accumulation was to allow the systematic reduction of re/production costs for capital.

Today we are witnessing that strategy's implosion. The web of life is rapidly moving from a source of Cheapness to an unavoidable vector of rising costs. The Biotariat is in open revolt. In place of the "limits to growth," the world-ecological alternative offers an alternative: Not only is "Another world possible" - the unofficial slogan of the World Social Form but:Another class struggle is possible. We have in the Great Stagnation the revolt of the Biotariat - whose contribution to the revolutionary destabilization of capitalism has been underestimated by Environmentalists and Marxists alike. Although easily romanticized, grasping the web of life through the oikieos - the creative, gener-ative, and multilayered pulse of lifemaking - asks us to reexamine human solidarity with the rest of nature in ways that challenge the Promethean domination of life and that explore the communist possibilities for liberation:"the creatures too should become free." Foregrounding the oppressive and exploitative dynamics of work, life, and power, Planetary Justice prioritizes the abolition of the ProletarianBiotarian-Femitarian relation created through the Great Frontier after 1492. This is the challenge of the planetary class struggle in the last days of the Holocene.

\section{KEYWORDS}

World-ecology; climate history; capitalism; political economy; political ecology; sustainable development. 


\section{ntroducción}

El concepto de "frontera de las mercancías" se ha convertido en una especie de referencia conceptual para los estudiosos de la historia capitalista en las últimas dos décadas. Muchos han señalado mis primeras reflexiones sobre ello y sobre el auge del capitalismo como un momento decisivo en la historia medioambiental mundial. En una serie de ensayos escritos entre 1997 y 2002, esbocé una geografía histórica del capitalismo que situaba en primer plano lo que Walter Prescott Webb llamó en su día "la Gran Frontera”. La intuición de Webb (1952) consistía en entender cómo la historia del capitalismo había sido moldeada fundamentalmente por una serie de "beneficios inesperados" que apuntalaron el largo auge de la modernidad, que terminó, según dicho autor, durante la Gran Depresión de los años treinta. Ese diagnóstico no era tan absurdo como podría parecer. Sin duda, Webb no previó cómo la acumulación militarizada y el desarrollismo de la Guerra Fría producirían nuevos y robustos "estímulos especiales" para impulsar la acumulación mundial en la edad de oro de la posguerra (Sweezy y Magdoff, 1972; Baran y Sweezy, 1966)'. Pero había captado el problema: la acumulación mundial depende de las fronteras de la naturaleza barata cuyo cierre dio paso a nuevas formas de inestabilidad económica y agitación política. Las tendencias históricas-mundo, así como los puntos de inflexión históricos-mundo invariablemente tienen una relación no lineal. Es un problema para el que las bolas de cristal no sirven, pero los libros sobre el largo siglo $X X$ sugieren la intimidad de esa relación no lineal. Una era que comenzó con un nuevo imperialismo y una "segunda" revolución industrial termina con una crisis planetaria marcada por un triple cierre: no sólo del largo siglo $X X$, sino del Holoceno y del capitalismo histórico.

La frontera es una metáfora resbaladiza. Hoy en día, suele invocar algo llamado "colonialismo de colonos". En contraste con una literatura anterior que ponía en primer plano la formación de clases, la moda académica actual propone una metafísica de "choque de civilizaciones" que muestra poca preocupación por ello, incluso en sus registros coloniales e imperialistas ${ }^{2}$. La Gran Frontera de Webb, de hecho, desprende un cierto tufillo a estas dinámicas. Pero, es posible hacer una reconstrucción dialéctica extrayendo elementos de las tres formulaciones parciales si se entiende la Gran Frontera como parte integrante de un proyecto civilizador, de apropiación imperialista de tierras y de formación de clases racializadas, así como de una historia de creación de un entorno que transformó la vida planetaria de una manera sin precedentes. En mis formulaciones originales luché contra todo esto, y lo he seguido haciendo desde entonces (Moore, 2000a; 2000b; 2000c; 200 I; 2002; 2003a; 2003b; 2003c; 2003d; 2004a y 2004b).

El concepto de frontera, por muy tosco que fuera, me ayudó a ver que el capitalismo no se formó dentro de una Europa reificada para luego expandirse. El capitalismo se formó a través de la Gran Frontera. Las fronteras de las mercancías - sobre todo en la plantación de azúcar y la minería de plata - fueron las cristalizaciones más espectaculares de la Gran Frontera (aunque otras, como la "Gran Domesticación" del llamado trabajo femenino, también fueron decisivas) (Patel y Moore, 2017). Las fronteras, así, siguiendo esta interpretación, no eran límites lineales en los bordes de una proyección cartográfica (que es en sí misma una tecnología fronteriza): eran

En el capítulo "Age of Restructuring”, John Bellamy Foster (1989) ofrece un tour de force resumiendo los estímulos especiales —-"factores de desarrollo autolimitantes"-.

Contrastar, por ejemplo, McMichael (1984) con Hixson (2013). En estudios de frontera véase la negación de clase de Barbier (2015).Algunos estudios se toman en serio la frontera de las mercancías, como Marley (2016). 
estrategias de poder, beneficio y vida, así como puntos geográficos de sus contradicciones. Las fronteras de las mercancías así, no eran, fundamentalmente, regiones como tales, sino patrones de movimiento interregional. Por ejemplo, la frontera mercantil del azúcar, en esta interpretación, era el gran arco del complejo azucarero/esclavista que se desplazaba a través del Atlántico capitalista (véase el cuadro I). Como observó Friedrich Engels en una carta de 1873 dirigida a Marx "identificar los diferentes tipos de movimiento es identificar los cuerpos mismos” (Engels en Banaji, 2010: 58), algo que se aplica fácilmente a las fronteras de mercancías.

TABLA I. La frontera del azúcar (1450- I 800)

\begin{tabular}{c|c} 
Región & Periodo primacía mundial \\
\hline Chipre & $1350-1470$ \\
\hline Madeira & $1480-1520$ \\
\hline Santo Tomé & $1540-1570$ \\
\hline Pernambuco & $1570-1620$ \\
\hline Bahía & $1620-1670$ \\
\hline Barbados & $1670-1720$ \\
\hline Jamaica y Santo Domingo & $1720-1790 / 1820$ \\
& Fuente:Jason W. Moore (2010e)
\end{tabular}

Esta inquietud geográfica no es una casualidad. La interminable conquista de la Tierra en pos de una infinita acumulación de capital son dos expresiones de un proceso singular: el surgimiento y la continua desaparición de la ecología-mundo capitalista (Moore, 2015a). El imperialismo es el pegamento que une ambos momentos. Sin embargo, la íntima conexión entre la conquista interminable y la acumulación infinita nunca se ha entendido bien, ni siquiera en la izquierda. Muchos siguen creyendo que el capitalismo continuará "hasta que se corte el último árbol" (Moore, 2017a) pero la principal regla de reproducción del capitalismo no es simplemente crecer o morir; es, en igual medida, conquistar o morir. Y es que, cada gran ola de acumulación se ha basado en un nuevo imperialismo, cuya principal tarea histórico-mundial ha sido crear y abaratar las clases trabajadoras: la unidad diferenciada de Proletariado, Femitariado y Biotariado 3.

El capitalismo no actúa sobre una Naturaleza externa - a pesar de los fetichismos de la teoría de sistemas-. El capitalismo se desarrolla a través de la red de la vida; estableciendo "fuerzas naturales específicamente explotadas" cuyas contradicciones activan progresivamente, en turnos sucesivos, el auge capitalista y la necrosis planetaria ${ }^{4}$. La tesis de la frontera de las mercancías insistió en que el capitalismo surgió a través de un nexo prodigiosamente generador de mano de obra barata, poder imperial y trabajo/energía no remunerados de suelos, bosques, arroyos y todo tipo de flora y fauna autóctonas no capitalizadas anteriormente. A partir de la estrategia de la Gran Frontera, se formaron no sólo proletarios modernos, sino también múltiples formas de

Biotariado es un término acuñado por el poeta Stephen Collis (2016). El Biotariado abarca todas las cosas en las que pensamos cuando oímos hablar de "servicios de los ecosistemas", pero también incluye a muchos seres humanos, que son desvalorizados en base a la abstracción dominante sobre la Naturaleza: principalmente a través de la raza, la nacionalidad, el género, la sexualidad, etc. etc. Véase especialmente von Werlhof (1988). El argumento de "poner la naturaleza a trabajar" proviene de Moore (20I5b).

4 La cita es de Karl Marx (1973). Para la activación de los valores negativos-formas de vida que constituyen barreras cada vez más insuperables para una renovada acumulación de capital, véase McBrien (20I6) y Moore (20I5a, 20I5c y 20I5d). Puede consultarse también el video "Negative Value defined by Jason W. Moore" en https://www.youtube.com/watch?v=KeE9yzAZEdw\&t=9s 
trabajo no remunerado socialmente necesario, principalmente, el Biotariado, entendido como el quantum de naturaleza extrahumana "puesta a trabajar" por el capital y el imperio, así como el Femitariado, referente a las relaciones abrumadoramente feminizadas de trabajo social-reproductivo no remunerado. Esta trinidad no es una combinación ecléctica y caótica, sino que diferencia y unifica el esfuerzo de longue durée de la burguesía imperial para "poner a trabajar a la naturaleza" de la forma más barata posible. Una estrategia de longue durée que surgió y se mantuvo a lo largo de los siglos, en el filo de la navaja de la Gran Frontera.

En lo que sigue, tomo la Gran Frontera -entendida como un proyecto de dominio imperial-burgués y un proceso socio-geográfico de sostenimiento de la acumulación de capital- como hilo conductor. Al hacerlo, espero suscitar un debate en torno a una amplia perspectiva sobre la frontera de las mercancías. Se trata de una tarea intelectual de gran envergadura en la que se corre el riesgo de ceñirse demasiado a la práctica del pasado o de romper por completo con las conceptualizaciones anteriores. Haré lo posible por enhebrar la aguja.

Este enhebrado exige una cierta ruptura con las convenciones académicas, pero tengo poco interés en contribuir a ellas. Como enseño a mis estudiantes de doctorado, la crítica no consiste en catalogar lo que el argumento $X$ y el enfoque $Y$ no hacen (mucho menos implica, como parece ser la norma hoy en día, escoger frases que puedan luego desvanecerse como un castillo de naipes). La crítica Dialéctica debe partir de una ética de la síntesis ${ }^{5}$, reconociendo que ninguna totalidad lo es todo, y que los puntos ciegos conceptuales y empíricos, una vez reconocidos e integrados, pueden cambiar el "movimiento del todo". La carga de la crítica consiste en revelar cómo la inclusión de la realidad A o B cambia la interpretación del cambio histórico y conduce a nuevas estrategias narrativas. Como he argumentado en otro lugar, el problema de la Aritmética Verde - la suma de Naturaleza y Sociedad - es su enfoque aditivo y no sintético. El lector atento observará cómo los elementos clave de lo que sigue son contribuciones a una autocrítica basada precisamente en ese espíritu de síntesis, que exige, como diría Marx, una estrategia "despiadada" de reinvención filosófica, teórica y conceptual-histórica (Gaffney et al., 2020). Esta alternativa demuestra cómo la incorporación (o la exclusión) de un determinado conjunto de relaciones histórico-geográficas permite o inhabilita un argumento sobre puntos de inflexión específicos y patrones de desarrollo en la historia del capitalismo (Moore, 20I7b).

A la luz de esto, he reelaborado mi contribución a la reflexión sobre la Gran Frontera en tres partes, centrándome sucesivamente en la historia del medioambiente, los proyectos civilizadores y la crisis climática actual, en lo que yo llamo la "Gran Implosión”. En una especie de camino largo y sinuoso, quiero vincular estas reflexiones a formas de estudiar las fronteras del capitalismo de la Naturaleza Barata que resistan varias tentaciones: el reduccionismo de las mercancías, una tesis neomalthusiana de agotamiento del suelo y el negacionismo de clase del "colonialismo de los colonos". En la primera parte, vuelvo a exponer los contornos histórico-geográficos de la frontera de las mercancías en el surgimiento del capitalismo. Mi premisa es que la figuración histórica de los orígenes, los puntos de inflexión y los patrones de desarrollo están calibrados de forma más o menos directa con nuestras evaluaciones políticas de la crisis climática, una cuestión que abordamos en la tercera parte. Comienzo revisando los elementos centrales de mi primer argumento sobre la frontera de las mercancías, que desarrollé para comprender el cambio de época

Gracias a John P.Antonacci por esta frase, ética de la síntesis, y por permitirme emplearla aquí. 
en la historia medioambiental mundial después de 1492. Con demasiada frecuencia, tanto los académicos como los estudiantes juegan con la especificidad histórica, y, sobre todo, con la especificidad histórico-mundial (como si la "historia mundial" del capitalismo fuera una generalidad de alguna manera "menos real" o "más teórica" que la historia regional ${ }^{6}$ ). El argumento de la frontera de las mercancías está unido dialécticamente a la especificación de los puntos de inflexión en la historia del capitalismo, desde la transición original hasta las crisis de desarrollo que marcaron la transición de una era del capitalismo a la siguiente. No puedo decir si una narrativa de la frontera de la mercancía desvinculada de esta prioridad interpretativa es útil o no. Cabe destacar que la frontera de la mercancía nunca se concibió como un concepto único o una observación empírica abstracta que "generaliza" sobre el capitalismo. Lo cierto es que fue tomando forma para explicar la dinámica específica del ascenso del capitalismo como ecología-mundo del poder, el beneficio y la vida (Moore, 2007a). En varios momentos desde principios de la década del 2000, he llegado a observar que cada nueva era de desarrollo capitalista emerge a través de nuevas estrategias de frontera, centradas en nuevas mercancías estratégicas, incrustadas dentro de nuevos proyectos civilizadores y nuevos hegemones creadores de mundo (Moore, 2007b, 2008, 2009, 20 I0a, 20 I 0b, $2010 c, 2010 d, 2010 e, 201$ la y $201 \mathrm{lb}$ ).

A partir de este esbozo histórico-geográfico, desgloso un doble argumento. Uno es que las fronteras de las mercancías no tienen que ver estrictamente con las mercancías o la mercantilización “en amplitud o en profundidad” (Lenin, 1964). Tienen que ver con el imperialismo, que es siempre el modo de formación de clase preferido por la burguesía mundial. El imperialismo es la política mundial de la tendencia (y contratendencia) a la caída de la tasa de ganancia (Lenin, 1963; Magdoff, 1989). Se basa no sólo en la fuerza militar sino también en la violencia ideológica de los Proyectos Civilizadores. Este es el tema central de la segunda parte. Sin duda, la mercantilización está en juego; pero reducir la historia a las fuerzas del mercado repite un error neosmithiano. No capta la centralidad del imperialismo y sus mecanismos de poder de clase para forjar las principales fronteras mercantiles del capitalismo. Las relaciones capitalistas de la Naturaleza —utilizo la mayúscula para subrayar la abstracción real- siempre están mediadas políticamente por los estados que persiguen la creación y reproducción de un "buen entorno empresarial” (O'Connor, 2018; Parenti, 2016 y 2020). El proyecto (geo)político de gestionar y asegurar las redes de vida para el capital depende de un proyecto geocultural que hace posible la violencia práctica del fetichismo de las mercancías en las fronteras (Moore, 2018a). Este es el fetichismo civilizatorio. Sus expresiones se encuentran en los sucesivos y superpuestos proyectos cristianizadores, civilizadores y desarrollistas de los grandes imperios, expresados intelectualmente durante mucho tiempo por figuras que van desde Francisco de Vitoria a WaltW. Rostow. Estos proyectos reproducen y reinventan las abstracciones dominantes de Civilización y Salvajismo (Escobar, 20 I I) —después de 1949, la división del Cuarto Punto de Truman entre el "mundo subdesarrollado" y el "mundo no desarrollado"- . Nuestro lenguaje conceptual de Sociedad y Naturaleza, forjado en la época de la primera gran campaña de limpieza étnica de Inglaterra en Irlanda, reproduce discursivamente estas abstracciones reales (Patel y Moore, 2017).

Un segundo argumento pondrá de relieve los tejidos conectivos que unen nuestras evalua-

\footnotetext{
Una posición ahora explicitada por la tesis del Plantacionoceno y su alianza con el "Earthbound" de Latour -cuya tarea ideológica concreta es borrar la clase y el capital en la creación del mundo moderno en favor de un choque de civilizaciones de sangre y tierra-. Véase Bruno Latour (2018) y Wolford (202I).
} 
ciones histórico-geográficas sobre la creación de fronteras capitalistas con la crisis climática actual. En la tercera parte, enmarcaré la crisis planetaria como la unión de dos momentos fundamentales: una creciente crisis de creación de vida, registrada ampliamente en las literaturas sobre el clima y la biodiversidad; $y$ una creciente crisis de creación de beneficios, registrada ampliamente en el discurso sobre el "estancamiento secular" (Summers, 2016; Bellamy Foster y Yates, 2014). Estos dos momentos se combinan de forma desigual en el carácter geohistórico de la crisis climática en el que el punto de inflexión geofísico se expresa en la desestabilización de una trinidad nacida en el siglo XVII: la división de clases, el patriarcado y el apartheid climáticos (Moore, 2019). La crisis climática del siglo XVII impulsó la Gran Frontera como estrategia de acumulación, asumiendo su forma moderna entre 1550 y 1700 como solución climática a la "crisis general” de la época: una era de guerra interminable, crisis política endémica e inestabilidad económica. El florecimiento de la Gran Frontera como una revolución productivista en toda regla —la Revolución de las Plantaciones - inauguró el Gran Abaratamiento, un descenso secular a largo plazo del precio (composición del valor) de los Cuatro Grandes insumos: fuerza de trabajo, alimentos, energía y materias primas7. Lo que denominamos como "los Cuatro Baratos" histórica específicamente capitalista, y su servicio de época a la acumulación mundial consistió en permitir la reducción sistemática de los costes de re/producción del capital. Hoy asistimos a la implosión de esa estrategia. La red de la vida está pasando rápidamente de ser una fuente de insumos baratos a constituir un vector inevitable de aumento de los costes. El Biotariado está en abierta rebelión.

\section{Las fronteras de las mercancías y los orígenes de la crisis planetaria: Proletariado, Biotariado y Femitariado en la Gran Frontera}

La Gran Frontera es un debate Transicional (Hilton, 1976). La larga conversación sobre los orígenes del capitalismo nunca desaparecerá y en él, las cuestiones geográficas, pese a ocupar un lugar destacado, han sido cuidadosamente evitadas. Ya puede buscarse a lo largo y ancho de este debate una historia del medioambiente, que nunca encontrará una historia del clima ${ }^{9}$. El resultado es una geografía de la transición que debe más a von Thunen que a Marx ${ }^{10}$. Los dos momentos las geografías y las historias ambientales de la Transición - vienen resaltados en la creación de la Gran Frontera. Ignoramos estas dinámicas por nuestra cuenta y riesgo. Desvincular la historia de los modos de producción de la coproducción del espacio - que también es la coproducción de la vida - da lugar a una narrativa parcial con implicaciones peligrosamente parciales para la política planetaria.Sobre todo, conduce a nociones fetichizadas de poder y política de clase. Parafraseando un viejo eslogan anarquista, no se puede reventar una relación socio-ecológica. Una historia del poder y del beneficio sin una historia de la vida, reproduce invariablemente una historia medioambiental sin clase y una lucha de clases sin redes de vida, una grieta epistémica que mantiene la gran división

\footnotetext{
Véase, a este respecto, la clase dada por Jason W. Moore en el Departmento de Estudios Africanos y de la Diáspora Africana de la Universidad de Wisconsin-Milwaukee el 6 November, 2020 titulado "On the Origins of Climate Apartheid: Climate Class \& Colonialism in the Making of Planetary Crisis".Video disponible en https://www.youtube.com/watch?v=bV4uR8iO2-8

8 Para que quede claro, después de varios años recibiendo unas alucinantes difamaciones por parte de John Bellamy Foster y sus colegas: el precio, en mi trabajo, ha sido siempre una forma de abreviar sobre la composición del valor en el sentido clásico marxista -uno que incluye el trabajo no remunerado en la red de la vida-

9 Una notable excepción a ello la conforman Wallerstein (1974) y Moore (2003a y 2003c)

10 La más clara expresión de ello puede encontrarse en el formalismo de Wood (2017). Robert Brenner (I977) no está muy lejos de aceptar las premisas geográficas del nacionalismo metodológico de la Guerra Fría bajo la bandera de la ortodoxia marxista
} 
entre los movimientos obreros y medioambientales.

¿Cómo se conjugan el capital, la clase y las redes de vida en la historia del capitalismo? Mi camino ha sido poderosamente moldeado por el primer gran esbozo de materialismo histórico de Marx y Engels en la Ideología Alemana. Apelar a Marx en cuestiones históricas, por supuesto, no resuelve nada. Sin embargo, dada la huida de la geografía, puede ser fructífero revisar su extraordinario tejido de geografía física, creación de entornos y formación de clases. Pasando, como siempre, de las abstracciones generales a las determinadas,

el primer hecho que hay que establecer [en una investigación histórico-materialista] es la organización física de los individuos y su consiguiente relación con el resto de la naturaleza. Por supuesto, no podemos entrar aquí en la naturaleza física real del hombre, ni en las condiciones naturales en las que el hombre se encuentra - geológicas, oro-hidrográficas, climáticas, etc.- Todo escrito histórico debe partir de estas bases naturales y de su modificación en el curso de la historia por la acción de los hombres (Marx y Engels, 1976).

Marx y Engels no recomendaban simplemente ofrecer unas cuantas observaciones introductorias sobre el "contexto medioambiental" para luego seguir adelante, como si los entornos y la creación de entornos fueran epifenómenos a la formación de clases, los modos de producción y las divisiones del trabajo entre la ciudad y el campo. Más bien, cada una de estas últimas -más determinadas - abstracciones encarnan y rehacen "su consiguiente relación con el resto de la naturaleza" (Murray, 2013; Moore, 2015a y 20l7b). Es a través de la Gran Frontera que las agencias proto-capitalistas - cada civilización tributaria disponía de una parte de estas - se enfrentaron a un mosaico de "condiciones naturales" y promulgaron una serie de "modificaciones". La problemática histórico-geográfica de la Gran Frontera, así, se pregunta cómo esta totalidad socio-ecológica favoreció una resolución capitalista y no tributaria de la crisis feudal.

¿Qué impulsó la Gran Frontera? No fue el comercio, ni la codicia, ni una metafísica de la expansión europea, como indican los argumentos aduladores del "milagro europeo" o del "colonialismo de colonos" declinante. Recordemos que los albores de la Pequeña Edad de Hielo (c. I300-1850) detonaron la múltiple crisis socio-ecológica del feudalismo, que condujo directamente al colapso de la agricultura feudal en la Gran Hambruna (13I5-1322) y los brotes epizoóticos asociados, amplificando las contradicciones de clase a fuego lento. El siglo siguiente se caracterizó por una "guerra de clases generalizada entre los señores y los campesinos", cuyos contornos fueron definidos por el clima de la Pequeña Edad de Hielo y el resurgimiento de enfermedades catastróficas (Wallerstein, 1974, p. 24). Para ser claros, la crisis no era una dinámica maltusiana, sino marxista: como los historiadores marxistas han subrayado durante mucho tiempo, las cuestiones de la fertilidad del suelo tenían que situarse dentro de las relaciones de clase del feudalismo (Patel y Moore, 2017; Hilton, 195I). Para abreviar la historia, los señores perdieron la guerra de clases —no por no lucharla_porque el excedente feudal se contrajo drásticamente en la coyuntura climática-clasista. La Europa feudal entonces se desmercantilizó y la balanza del poder de clase en el continente se inclinó a favor del campesinado.

La entrada en la Gran Frontera fue una conquista a modo de síntesis continua. Combinaba 
las estrategias premodernas de la guerra santa y el comercio armado con un énfasis novedoso: mano de obra barata a cualquier precio. La productividad de la mano de obra, no de la tierra, era —después de 1492, pero especialmente después de 1550 - lo que importaba. Había que crear y asegurar nuevas clases trabajadoras si se quería establecer una nueva base de enriquecimiento. Habiendo perdido la lucha de clases en el corazón de Europa, los asediados estratos gobernantes tributarios del continente -incluidos los comerciantes-banqueros de lugares como Génova y Flandes - miraron hacia la frontera. Pero las fronteras no sirven de nada sin una mano de obra que las trabaje, y la proletarización moderna requiere unas formas de poder territorial totalmente nuevas. Después de 1492, en un abrir y cerrar de ojos de la historia mundial, la encomienda, una concesión de tierras utilizada ampliamente en la Reconquista, se reinventó como una concesión de mano de obra en las Américas; produciendo feroces debates teológicos e incluso políticos, pero la suerte ya estaba echada.

La Gran Frontera, como frontera de mano de obra barata -en contraste con Europa occidental - fue fundamental para las mayores innovaciones del capitalismo temprano. Los momentos definitorios de la Transición se aglutinaron en la Gran Frontera: nuevas organizaciones productivas, sistemas de crédito, estructuras imperiales, proletarización coercitiva, tecnologías que marcaron una época (sobre todo el nexo construcción naval/barcos/cartografía). Todo ello permitió a los actores imperiales, financieros, señoriales y otros superar su histórica derrota de clase a lo largo del siglo XIV. Las nuevas fronteras no eran una salida demográfica para una Europa reificada y llena de Testigos reificados, sino un conjunto de oportunidades políticamente aseguradas para el beneficio y la acumulación de capital (de hecho, dichas oportunidades fueron los propios mecanismos de producción de estos fetiches; ¡evitemos poner las carretas delante de los bueyes!). Las antiguas fronteras demográficas, comerciales y de recursos se volvieron del revés —junto con todo lo demás - después de 1450. Las nuevas fronteras de las mercancías —encabezadas por los imperios financiados por la deuda - forjaron no sólo estrategias para ampliar el "pastel económico", sino que transformaron el carácter de la propia acumulación de excedentes".

La exclusión de estas nuevas estrategias de creación de frontera ambiental en el debate sobre la Transición es sorprendente. Por ello, a continuación, repasaremos la historia del medioambiente. El Debate contemporáneo se remonta al medio de la Guerra Fría, momento en el que el poder de los trabajadores en los países imperialistas y las luchas antiimperialistas en el Tercer Mundo estaban en auge. Por entonces, se entendía que la orientación estratégica de uno hacia la lucha por el socialismo mundial dependía de su visión histórica — de ahí los sorprendentes paralelismos entre el socialismo y el capitalismo "en un país" y el "internacionalismo" proletario y burgués ${ }^{12}$. El Debate de la Transición fue (y sigue siendo) un debate que unifica una narrativa de los orígenes del capitalismo con una evaluación política de la crisis capitalista. Retomando un viejo chiste de Marx, se puede cerrar la puerta principal del Debate de la Transición, pero siempre

\footnotetext{
"Véase especialmente Wallerstein (1974). Una lectura socio-ecológica deWallerstein se ofrece en Moore (2003a y 2003c). Estas implicaciones vienen profundizadas en Patel y Moore (2017), Moore (2017c y 20I8a).

12 La oposición clásica entre Robert Brenner y Wallerstein no es —como a menudo se afirma- entre "producción" e "intercambio". La diferencia fundamental gira en torno al encuadre respectivo de la geografía de la lucha de clases y, crucialmente, sobre el modo de construir "unidades de observación" con y dentro de las "unidades de análisis". La afirmación de que el esquema interpretativo de Wallerstein pivota sobre el mercado mundial es una canallada. La diferencia fundamental entre ambos reside en la lucha de clases de Brenner en "un país" y la de Wallerstein en la división transatlántica del trabajo. Véase Wallerstein (1974) y Brenner (1976). Podemos observar que Wallerstein pone en primer plano la Gran Frontera, mientras que la unidad de análisis de Brenner descarta no sólo las fronteras, jsino incluso la subordinación colonial de Irlanda en la transición del capitalismo!
} 
encontrará una forma de entrar por la ventana de la cocina. Lo mismo ocurre con el Antropoceno popular actual y las alternativas del Capitaloceno (Moore, 20I7d y 2017e). No nos equivoquemos, la conversación sobre el Antropoceno es un debate sobre la Transición.

A partir de la década de 1470 —en regiones hasta entonces oscuras como el Erzgebirge y Madeira - la lógica medieval de auge y caída se transformó por completo (Moore, 2007b; 2009; 2010e; Brenner, 1976). Sus beneficios enriquecieron no sólo a los potentados locales, sino a los financieros que hicieron posible las nuevas organizaciones productivas. Las recientes revoluciones productivas pusieron en marcha el cambio ambiental y la proletarización a una velocidad vertiginosa, cuyas contradicciones de clase estallaron en una insurrección abierta en I525. Los Fuggers y los Welsers financiaron el auge minero de Europa Central; los comerciantes flamencos y genoveses financiaron la revolución azucarera de Madeira. Fueron estos burgueses los que se beneficiaron —y en el caso de los Fugger, perecieron- a base de invertir en "capital real". $Y$ fueron estos beneficios acumulados los que financiaron las fronteras de las mercancías a través del Atlántico capitalista.

Estas contradicciones alcanzaron una masa crítica a mediados de siglo. Su condición previa fue la invasión colombina lanzada en 1492 caracterizada por la globalización de la "revolución militar" y, en la medida de lo posible, por el saqueo de oro y plata. No se trataba de una empresa directamente productivista, ni tenía por qué serlo. Sin embargo, en la década posterior a I549, los signos de crisis se encontraban por todas partes. Un giro productivista era claramente necesario - e inmediatamente reconocido en las Cortes de Europa-. Los portugueses asumieron la administración directa de Brasil (1549). Los españoles debatieron el destino de los pueblos indígenas en Valladolid (1550-5I). El español Felipe II se declaró en quiebra y el rey francés (Enrique II) vio "colapsar" sus finanzas en I557, precipitando la primera gran crisis financiera de la modernidad (Spooner, 1972; Moore, 2010c). Con sus casas fiscales en llamas, los dos grandes rivales alcanzaron la paz en Cateau-Cambrésis en 1559, codificando lo que era obvio: ninguna gran potencia resolvería la crisis feudal mediante conquistas a lo Carlomagno y un nuevo imperium. "Europa no se convertiría en un imperio-mundo (Wallerstein, 1974). La extraordinaria inflación de los precios —la Revolución de los Precios - había abaratado el crédito y lo había hecho indispensable para la agricultura de cultivos comerciales en toda Europa, llegando rápidamente a lugares como Brasil y Barbados en el siglo posterior a 1549. Todo ello favoreció un giro productivista transatlántico después de 1549 (Tawney, 194I; Schwartz, 1985), transformando las fronteras imperiales en fronteras de las mercancías, no menos imperialistas por la metamorfosis.

Finalmente, en la década de 1550, los signos de empeoramiento del clima ya se hicieron evidentes, deteriorándose las condiciones climáticas rápidamente después de 1600. La coyuntura sociofísica, que en su mayor parte fue el resultado de un forzamiento natural, se vio amplificada por los genocidios inducidos por la esclavitud en el Nuevo Mundo donde la destrucción de pueblos provocó una dramática disminución del dióxido de carbono atmosférico - el pico de Orbis (1610) - que, a su vez, agravó el deterioro climático de Europa (Lewis y Maslin, 20I5). Este fue, como veremos, el momento geofísico inscrito en los orígenes de la división de clases, el apartheid y el patriarcado climáticos: la trinidad capitalógena que ahora nos conduce a toda velocidad hacia el infierno planetario (Moore, 2019). El resultado fue un "largo y frío siglo XVII" de guerras interminables, revueltas endémicas y turbulencias económicas (Le Roy Ladurie y Daux, 20I 3; Cameron, 
Kelton y Swedlund, 2016; Jones, 2014).

Lo que siguió fue el primer arreglo climático del capitalismo ${ }^{13}$. Esto reforzó los anteriores empujes del imperio y del capital a través del Atlántico, en sí mismos una respuesta a la coyuntura de clima y clase del largo siglo XIV. Este largo y frío siglo XVII fue, para un capitalismo emergente, el momento más desfavorable de la Pequeña Edad de Hielo. Aunque el término desfavorable sea deliciosamente impreciso. Baste decir que fue más que incómodo. Las condiciones climáticas más o menos comparables a las de los largos siglos $\mathrm{V}$ y XIV habían sido testigos de las crisis epocales del Occidente romano y de la Europa feudal' ${ }^{14}$.

¿Cómo, entonces, sobrevivió el capitalismo allí donde no lo hicieron las civilizaciones anteriores?

¿La respuesta corta? La Gran Frontera (Webb, 1954) ${ }^{15}$, aunque se trata de un reduccionismo brutal, por supuesto. Así que permítanme explicarlo. La conjunción clima-clase-finanzas de la década de 1550 contribuyó poderosamente a un giro productivista en las Américas y en Europa del Este ${ }^{16}$. Este arreglo climático se formó a través de un nuevo intercambio político centrado en el productivismo entre banqueros, imperios y productores de mercancías del Nuevo Mundo (Arrighi, 20I0; Patel y Moore, 2017; Moore, 2010f). El resultado fue una revolución medioambiental sin precedentes en cuanto a escala, alcance y velocidad. Su expresión superficial fue una revolución paisajística, pero su contenido real implicó una revolución audaz de la re/producción, el gobierno y la formación de clases. Hizo necesario el Proyecto de Civilización y su lógica cartesiano-gerencial (avant la lettre) de "pensamiento" y substancias "extendidas" —el tema de la segunda parte-, desarrolló formas novedosas y violentas de proletarización a través del Atlántico, incluyendo la esclavitud moderna y otras formas de trabajo racializado ${ }^{17}$. Fundamentó, además, la acumulación mundial dentro de estrategias de abaratamiento de las vidas y el trabajo necesarios para producir los Cuatro Baratos: trabajo y trabajo no remunerado, alimentos, energía y materias primas.

En este punto solo puedo caracterizar, de forma no exhaustiva ${ }^{18}$, los principales momentos fronterizos de las mercancías a lo largo de este largo y frío siglo XVII cuya muestra representativa incluye: I) la revolución azucarera de Brasil a partir de 1570 que se desplazó a Santo Tomé tras un auge momentáneo cortocircuitado por la resistencia de los esclavos; 2) la dramática reestructuración de Potosí a partir de I57I, que trasladó definitivamente la minería de plata capitalista de Europa Central a Perú; 3) la rápida sucesión de fronteras de mercancías forestales desde Noruega

\footnotetext{
13 Al respecto, nuevamente véase "On the Origins of Climate Apartheid: Climate Class \& Colonialism in the Making of Planetary Crisis".Video disponible en https://www.youtube.com/watch?v=bV4uR8iO2-8

14 Una excelente introducción a la historia del clima es la realizada por Brooke (20I4); sobre la severidad climatológica y la turbulencia social del largo y frío siglo XVII, existen ahora muchas contribuciones.Véase, por ejemplo, Parker (20I3) oWhite (20I7). Un resumen de referencia sobre la dinámica geofísica de la Pequeña Edad de Hielo es el realizado por Mann (2002).

15 Volveré a Webb en la tercera parte.

16 Véase, especialmente, Moore (2010c y 2010d) aunque esos ensayos no explican, sin embargo, el giro productivista en respuesta a los cambios climáticos.

17 "Cuando hace tres siglos los esclavos llegaron a las Antillas, entraron directamente en la agricultura a gran escala de la plantación de azúcar, que era un sistema moderno. Además, exigía que los esclavos vivieran juntos en una relación social mucho más estrecha que cualquier proletariado de la época. La caña, una vez cosechada, tenía que ser transportada rápidamente a lo que era la producción de la fábrica. El producto se enviaba al extranjero para su venta. Incluso la tela que vestían los esclavos y los alimentos que comían eran importados. Los negros, por tanto, vivían desde el principio una vida que era, en su esencia, una vida moderna" (James, 1989)

18 Pueden encontrarse referencias detalladas a estas y otras transformaciones epocales en Moore (2010c, 2010d, 20I7c y 20I8a).
} 
hasta Polonia y el noreste del Báltico que comenzó — de nuevo- en la década de 1570; 4) las agresivas ampliaciones de la agricultura cerealista del Vístula (y la consiguiente deforestación) después de 1550 que proporcionaron una protección indispensable contra la inseguridad alimentaria para el capitalismo holandés; 5) el surgimiento del "Potosí del Norte", la Stora Kopparberg sueca, que enviaba cobre (el litio del siglo XVII) a los plantadores de azúcar, fabricantes de armas y artesanos del otro lado del Atlántico; 6) el traslado de la construcción naval ibérica a América, donde lugares como Salvador de Bahía y La Habana contarían con importantes astilleros a principios del siglo XVII; 7) la notable expansión de las flotas pesqueras en el Atlántico Norte, que marcó un momento clave de la "Gran Caza" (Richards, 2003); y 8) la revolución azucarera en el Caribe, que primero llegó a Barbados, pero se extendió rápidamente a Jamaica y luego a islas francesas como Martinica y Santo Domingo.

Es imposible exagerar el carácter sin precedentes de esta temprana revolución ambiental capitalista. Tanto la escala como el alcance son impresionantes. Sin embargo, quizá lo más significativo sea su carácter temporal. En el largo y frío siglo XVII, el "proceso histórico [se] aceleró repentinamente de forma aterradora" (Burkhardt, 1979, p. 224). En ese momento, el antagonismo entre el impulso del capital para reducir el tiempo de rotación socialmente necesario se combinó sistemáticamente con los proyectos imperialistas para crear las condiciones para la apropiación del trabajo no remunerado: la acumulación por apropiación ${ }^{19}$. Esto marcó la formación moderna del Femitariado y el Biotariado - los momentos específicamente binarizados del trabajo reproductivo humano y extrahumano no remunerado necesarios para el régimen de Naturaleza Barata del capitalismo-. Ambos estuvieron, por tanto, vinculados dialécticamente a una extraordinaria (y extraordinariamente violenta) aceleración de la proletarización de género, racial y colonial (Federici, 2004; Linebaugh y Marcus Redike, 2013;Tilly, 1983). Esta Gran Proletarización —entendida como la unidad diferenciada de Proletariado-Biotariado-Femitariado- dependía de las dos fronteras fundamentales de la época: las fronteras de las mercancías a través de las Américas y Europa del Este, así como la Gran Domesticación, cuyo hilo conductor sostenía que el Hombre se situaba ante la Mujer como la Burguesía ante la Naturaleza (Patel y Moore, 2017). La Gran Proletarización y la Gran Domesticación eran dos caras de la misma moneda histórico-mundial, esenciales para el clima del siglo XVII. Sin la mano de obra barata no habría habido trabajadores que trabajaran en los campos, las minas, los talleres, los bosques y las ciudades del primer capitalismo, ni beneficios que extraer. Además, sin estas fronteras laborales extraídas a la fuerza, los límites de la apropiación del trabajo/energía extrahumana (y el cambio medioambiental asociado) eran insuperables. Toda zona de sacrificio medioambiental -entonces como ahora- dependía de los trabajadores, sucesivamente baratos y desechables.

Fue en esta coyuntura sociofísica cuando el arreglo climático del capitalismo emitió una “compresión espaciotemporal” que degradó no sólo el suelo, sino también al trabajador. Se in-

\footnotetext{
9 La acumulación por apropiación designa las relaciones y fuerzas extraeconómicas en curso que combinan la represión salarial, la subreproducción crónica y la extracción de trabajo/energía no remunerada al servicio de la acumulación de capital. Se solapa con la acumulación primitiva, así como con su dinámica de formación de clases y de capital, pero no se reduce a ella. Tampoco es reducible a la acumulación por desposesión y desplazamiento, que identifica un momento de desterritorialización y reterritorialización fundamental en la geografía histórica del capitalismo. Históricamente, la acumulación por apropiación funciona con la misma facilidad para reterritorializar y limitar la movilidad de las clases trabajadoras, como atestigua la larga historia de la aldeanización desde el Perú colonial hasta la Sudáfrica del apartheid. Las dinámicas extraeconómicas que subyacen a la acumulación por apropiación comprenden no sólo la fuerza directa, sino también todo tipo de fuerzas jurídicas y geoculturales (por ejemplo, el racismo y el sexismo). Estos argumentos se destacan en Moore (20 I8a y $2015 a$ )
} 
trodujeron relaciones de poder, de beneficio y de vida que marcaron una época y que aceleraron el cambio histórico más allá de lo conocido antes de Colón (Harvey, 1989). Durante los milenios anteriores a 1492, el ritmo del cambio del paisaje se medía en siglos. Cuando los campesinos de la Picardía medieval se pusieron a limpiar la tierra en el siglo XII, tardaron dos siglos en reestructurar 12.000 hectáreas.

Ahora, avancemos hasta el noreste de Brasil, en la cúspide de su revolución azucarera. Durante la gloriosa década de 1650, los ingenios azucareros de Bahía obligaron a destruir 12.000 hectáreas de bosque... cada año.

La destrucción resultante de la selva atlántica fue, por tanto, una dinámica de clase.Algunos humanos, poseedores de dinero y poder, dirigían el trabajo de otros humanos - icon qué facilidad olvidamos que el esclavo de la plantación era también un proletario de la plantación! ${ }^{20}$ - Estos proletarios eran - como siempre, en condiciones de superexplotación racializada y de génerodesechables. La devastación de "la tierra" era el producto de un régimen que destruía al trabajador y enriquecía a los burgueses, en este caso a los plantadores y a los comerciantes-banqueros que los financiaban. La lógica gerencial de ese régimen, como observa Schwartz en su clásico estudio del conflicto de clases en las zonas azucareras de Brasil del siglo XVII, era bastante simple: "extraer la mayor cantidad de mano de obra al menor costo posible" (hecho que Marx ya intuyó en el capítulo sobre la Jornada de Trabajo en El Capital). La frontera mercantil era un agujero negro demográfico: se calcula que un cuarto de millón de esclavos africanos que desembarcaron en Bahía y Pernambuco entre 1600 y 1650 murieron explotados. De hecho, en este periodo, el noreste de Brasil apenas lograba mantener una población esclava de apenas 60.000 personas (tampoco hemos considerado la desgarradora mortalidad del proceso de tránsito).

El agotamiento de la fuerza de trabajo en los campos y bosques suponía no sólo la asunción de la existencia de fronteras terrestres de abundancia aparentemente ilimitada, sino también de la disponibilidad de fronteras laborales de África. Para cada acaparamiento y ocupación de tierras, había que encontrar, asegurar y suministrar fuentes de fuerza de trabajo fresca" "físicamente no corrompidas" y es que, cada frontera de las mercancías supone una nueva frontera de trabajo.Y así fue como la frontera del azúcar se unió a las fronteras de la esclavitud en África, cuya dinámica política autónoma se articuló cada vez más con el "mercado de trabajo" recién racializado del comercio transatlántico de esclavos. La revolución azucarera brasileña coincidió con el redireccionamiento geográfico de la trata de esclavos hacia el sur, en dirección a Angola pues, en los albores del siglo XVIII, la frontera esclavista había agotado los suministros de la costa angoleña y se dirigía rápidamente hacia el interior (Miller, 1988; Thornton, 1992).

Todo ello contribuye a aportar la necesaria visión geográfica que requiere el enfoque

20 Sobre la proletarización de las plantaciones y las luchas de clase transatlánticas del largo y frío siglo XVII, véase Linebaugh y Rediker (20I3). El debate sobre el carácter proletario de la esclavitud moderna se remonta a Marx, y no lo retomaré aquí. Sin embargo, desde el punto de vista del capital, el esclavo de plantación se reproducía a través del circuito del capital. La falta de libertad jurídica era necesaria para esa reproducción. Pero debemos resistir las tentaciones de un excepcionalismo esclavista a este respecto. Los límites jurídicos de los proletarios no se limitan a la ideología racista; la observación se aplica igualmente, aunque de forma distintiva, a la abstracción dominante referente a "la Mujer como necesaria para la proletarización”. Existe una fuerte tendencia a conceder un peso indebido a las normas de propiedad burguesas eurocéntricas sobre la proletarización realmente existente. El hecho de que un esclavo fuera una propiedad formal y pudiera ser comprado y vendido sitúa al esclavo de la plantación en un extremo del espectro proletario, sin duda, pero no hace que ese esclavo sea menos proletario. Se ofrece un importante estudio del debate sobre la esclavitud y la proletarización en Walter Johnson (2004); la contribución de Sidney Mintz (1978) también ha sido muy citada pero raramente comprometida.

${ }^{21}$ La frase proviene de la traducción de Moore y Aveling de "El Capital” de Karl Marx (1967: 256) 
de la frontera de las mercancías: las propias estrategias de "golpear y huir ecológicamente" que apuntalan la rápida creación y apropiación del Proletariado y el Biotariado aseguraron su relativo agotamiento socioecológico siguiendo un patrón evidente. En una región tras otra, la rentabilidad regional se tambaleó, de nuevo en relación con los posibles emplazamientos verdes en las fronteras. De manera crucial, como observa Marx sobre el agotamiento de la naturaleza humana en la producción capitalista, este es posible debido a la propia estrategia de frontera, de ahí la dependencia del capital hacia el imperio (y su intercambio político con él). El desplazamiento de Brasil al Caribe después de 1650 es un buen ejemplo. Las fronteras de las mercancías eran patrones de movimiento geográfico, producidas por sus antagonismos socio-ecológicos. Si mis formulaciones originales se acercaron peligrosamente a un marxismo neomalthusiano — retroalimentando esencialmente una tesis de agotamiento del suelo más antigua-, las sucesivas elaboraciones realizadas desde entonces han dejado claro que este patrón de movimiento geográfico estaba impulsado por una ecología compleja y de múltiples capas de poder, beneficio y vida. En estos estudios sobre el agotamiento socioecológico, uno se enfrenta rápidamente a una tentación sustancialista: ver este como el agotamiento de las sustancias en lugar de las relaciones que implican a las propias sustancias. Esta cuestión, sin embargo, es cualquier cosa menos metafísica. El agotamiento de las sucesivas fronteras mercantiles fue tendencialmente —y sobre el terreno, cada vez más — sobredeterminado por la revuelta proletaria. Por ejemplo, la revolución azucarera de Haití fue detenida en seco por la insurgencia proletaria, no por el agotamiento del suelo (Fick, 2000; James, 1989; Schwartz, 1992) ${ }^{22}$.

El agotamiento del suelo y del trabajador fue, en efecto, fundamental, pero no debe olvidarse que la frontera de las mercancías era a la vez regional y sistémica. Los esclavos caribeños, el azúcar y los suelos fueron figuras histórico-mundiales, y deben situarse dentro de los flujos de capital, la geopolítica y las transformaciones de la industria metropolitana en todo el mundo, como demostraría la Segunda Esclavitud después de 1793 (Tomich, 2003). El rastro de la devastación socioecológica que siguió a las fronteras de las mercancías se sitúa, por tanto, de forma más eficaz dentro de dos capas histórico-geográficas: los movimientos entre regiones, así como entre las sucesivas hegemonías mundiales y los regímenes ecológico-mundiales en los que están integrados. Esto nos permite unir los proyectos de la clase imperial-burguesa de rehacer la naturaleza mundial junto con la apertura de fronteras mercantiles específicas para producir, en una era, las condiciones para nuevas ( $y$ ampliadas) fronteras mercantiles en la siguiente. El aumento de la demanda existió, pero esto sólo explica una parte del movimiento geográfico. "La mercancía" y el "mercado mundial" desempeñan su papel, pero los aumentos más prodigiosos del consumo - como demuestran el algodón y el azúcar - siguieron a los momentos más prodigiosos de expansión de la producción (Moore, 20I7a). Las fronteras de las mercancías permitieron la industrialización metropolitana, que a su vez reforzó las presiones para intensificar la producción. Este antagonismo expresaba una poderosa contradicción —entre la expansión de la acumulación de capital y la simple reproducción de la vida - que produjo la frontera de las mercancías: la sobreexplotación secuencial de una región tras otra. El movimiento de la producción de mercancías primarias hacia nuevas fronteras implicaba, y de hecho necesitaba, el avance de la producción de mercancías primarias hacia fronteras aún más nuevas cuya "fertilidad natural" podía "actuar como un aumento del capital fijo" (Marx, 1973, p. 748).

22 Sobre el "punto de inflexión" de la Revolución Haitiana y la transición hacia una política revolucionaria semiproletaria que "presagió las revoluciones proletarias y anticoloniales del siglo XX”, véase Eugene D. Genovese (I98I). 
Lejos de ser una dinámica geofísica, este movimiento de puesta en funcionamiento de las redes de vida — la formación del Biotariado - estaba necesariamente ligado a los Proyectos Civilizadores, a los que ahora nos referiremos.

\section{Las fronteras de las mercancías y el proyecto civilizador. De lo "real" a las abstrac- ciones gobernantes}

La tesis de la Gran Frontera ofrece una alternativa a los modelos imperantes de expansión capitalista y de cercamiento planetario. Concuerdo con el argumento de que existe una lógica económica en la modernidad, y que esta lógica obliga al agotamiento en serie de las redes de vida.Acerca de esta posición, impera una versión neoclásica que hace hincapié en la racionalidad del mercado y en las capacidades tecnocientíficas para sustituir un recurso "escaso" por otro. Sin embargo, existe también una variante radical que incide en la narrativa catastrofista: la acumulación de capital es una colisión inevitable con la red de la vida. Ambas tienen la virtud de insistir en que la modernidad se desarrolla a través de un modelo de acumulación de capital, aunque desde premisas muy diferentes. Esto es lo que he llamado el modelo de la "Aritmética Verde" ¿El problema? La economía sumada a la ecología no cuadra. En el mejor de los casos, dispondremos de una abstracción general que combina "concepciones caóticas" arrancadas de su especificidad histórica (Marx, 1973, p. 100).

Un segundo modelo considera la modernidad como un choque de civilizaciones. En este esquema de cosas, "la fuente fundamental de conflicto... [no es] principalmente ideológica ni principalmente económica. Las grandes divisiones entre la humanidad y la fuente dominante del conflicto... [son] culturales" (Huntington, 1993, p. 22). En la expresión crítica de esta, el conflicto entre opresores y oprimidos pasaría al centro del escenario, alineándose las simpatías claramente con los segundos ${ }^{23}$. En ambos casos, sin embargo, la civilización —así como el racismo en general— se convierte en "una especie de hecho ontológico de la existencia política" (Said, 2000). Los orígenes de la civilización europea y de la formación racial encuentran sus raíces en un pasado lejano y decididamente premoderno ${ }^{24}$. Hoy en día, esta tendencia se expresa bajo la bandera del "colonialismo de colonos" y el capitalismo racial.Va más allá del economicismo de la Aritmética Verde al identificar correctamente la dominación geocultural y política en la formación del mundo moderno, pero se queda atrás al borrar la distinción entre la lógica del capital - a menudo la ignora por completo- y el terreno geocultural de las luchas de clase a favor y en contra de la superexplotación. Al igual que la Aritmética Verde, esta posición comercia con concepciones caóticas.Y, al igual que la teoría neoliberal, tiende a abstraer o minimizar radicalmente la explotación de clase $-y$ la política de clase, a menudo en formas nacionales y raciales - de la historia del capitalismo como ecología del poder, el beneficio y la vida. Sus desagradables implicaciones pueden encontrarse en la reciente "defensa" de Latour de la "patria europea" (Latour, 2018). Frente a ello, la alternativa dialéctica, especificada por figuras como Harry Haywood ya en 1933, identificaba la dialéctica de

\footnotetext{
23 La exploración que Asad Haider hace de esta cuestión en "In the Shadow of the Plantation”,Viewpoint Magazine (I3 de febrero de 20 I7) es indispensable.

24 Véase, por ejemplo, Robinson (1984) que es, además, explícito al afirmar que el capitalismo moderno temprano no es —realmentecapitalismo.
} 
la "cuestión nacional colonial” y la "revolución proletaria"25.

La tesis de la Gran Frontera une estos dos momentos - la lógica del capital y el pivote geocultural de la dominación - con la historia medioambiental. Rechaza la concepción de las metáforas de la "huella" para comprender el doble registro de la naturaleza: como red de vida y como abstracción dominante producida a través de los proyectos civilizadores y sus múltiples opresiones, altamente binarizadas (Moore, 2018b; Hage, 2017). La creación del medioambiente es, como subraya Marx, una dialéctica continua de transformación mutua: el trabajador ("naturaleza interna") y las redes de vida ("naturaleza externa") se producen mutuamente, pero nunca de la misma manera, siempre asimétrica, siempre histórica ${ }^{26}$ (Marx, 1967). Desde este punto de vista, podemos hablar de algo llamado capitalismo porque la reproducción ampliada del capital y sus reglas definidas de reproducción son hegemónicas, cada vez más en la larga duración de la Gran Frontera. La "lógica del capital" no es una abstracción del pensamiento, sino una abstracción real, una fuerza operativa que rehace la vida planetaria, reproducida por la acumulación primitiva (Sohn-Rethel, 2020). Es lo que los marxistas llaman la ley del valor (Moore, 2014) cuyas "leyes inmanentes" sobre la competencia capitalista recompensan a los que compiten eficazmente, y castigan a los que no lo hacen.

¿La trampa? La lógica del capital es impotente — de hecho, no puede madurar - sin la dominación geocultural y el poder territorialista. Los capitalistas, como actores económicos, no son aptos para crear buenos entornos empresariales. La capacidad de hacer avanzar la tasa de ganancia en la lucha competitiva mundial está fundamentalmente condicionada por el poder territorial y las ideologías de dominación —-sobre todo, el racismo, el sexismo y los Proyectos Civilizadores en los que están inmersos-. Al igual que el restablecimiento de la energía barata, por ejemplo, puede ampliar las oportunidades para el capital que, de otro modo, estaría sobreacumulado, también lo hacen los proyectos civilizadores. Como bromea Barbara J. Fields ( 1990, p. 102) "nadie podía obtener beneficios cultivando [cultivos de plantación]... con métodos democráticos. Sólo los que podían obligar a un gran número de personas a trabajar [los campos] para ellos podían enriquecerse". Por lo tanto, la dinámica de la dominación mundial no era una fuerza metafísica que se situara al lado de la acumulación mundial, ni era reducible a una lógica económica estrechamente definida. Las mismas ideologías de dominación - y sus estructuras imperiales- que hicieron posibles las Naturalezas Baratas en el corazón de la acumulación mundial también se reprodujeron a través de la lógica del capital. A la hora de la verdad, el equilibrio de la dialéctica se resolvió por la fuerza armada. De ahí nuestra segunda crítica: no sólo el economicismo es indebidamente parcial, sino también el civilizacionismo y la invocación "caótica" de la opresión y la resistencia como metafísica.

En mis formulaciones originales, la frontera de las mercancías abarcaba, pero también se resistía, a la Aritmética Verde. Por un lado, situé en primer plano la historia medioambiental en un marco más o menos convencional. Por otro lado, conceptualicé esta historia medioambiental como inmanente a la ley del valor, un hilo conductor que me llevó a ver que la degradación

25 Véase Harry Haywood, “The Struggle for the Leninist Position on the Negro Question in the United States," The Communist, (September 1933) y James W. Ford, Negro's Struggle Against Imperialism (Nueva York: Provisional International Trade Union, Committee of Negro Workers, 1930).

26 La expresión más concisa de esta dialéctica de creación de entornos es la de Richard Lewontin y Richard Levins (I997)”Organism and environment", Capitalism Nature Socialism, 8(2, 1997), 95-98. 
medioambiental se extendía tanto al trabajador como al suelo. Esto desafiaba los argumentos antiobreros del "intercambio ecológicamente desigual" (Moore, 2000b).Así, al interiorizar las contradicciones metabólicas y de clase de la frontera de las mercancías dentro de la ley del valor, se me abrieron nuevas perspectivas. Pude ver cómo estas disposiciones metabólicas se articulaban estratégicamente con las contradicciones inmanentes del capitalismo en cuanto a poder y acumulación mundial. Para ello, el vínculo con el innovador relato de Giovanni Arrighi es instructivo. El capitalismo, argumentaba Arrighi, se reinventa a sí mismo a través de sucesivas y largas oleadas de acumulación lo que implica una reinvención de la relación del capitalismo con la vida planetaria ${ }^{27}$. La inquieta geografía del capitalismo dramatizada en las sucesivas "revoluciones organizacionales" de las superpotencias se unió dialécticamente a las revoluciones en las formas de organizar las naturalezas históricas — revoluciones que incluían las dimensiones geoculturales de la hegemonía mundial tanto como nuevas formas de imperialismo botánico, revoluciones agrícolas y urbanización planetaria (Moore, 20l la) -

Esta línea de marcha se centró, por tanto, en una estrecha, aunque desigual, relación entre las secuencias regionales de auge y caída —el patrón de "sobreexplotación secuencial" de la frontera de las mercancías - y las reglas de reproducción del capitalismo28 (Gadgil y Guha, 1994, p. I2I). La ley del valor del capitalismo - la dinámica especificable de la acumulación sin fin-es una unidad diferenciada de poder, beneficio y vida (Moore, 2003b). Esto pone de manifiesto las conexiones internas entre la hegemonía ideológica, la dominación geocultural y la explotación de clase en la red de la vida. Cada momento de poder, ganancia y vida contiene contradicciones específicas que favorecieron la superexplotación mediante la creación de un nuevo dominio cosmológico: la Naturaleza.

La Naturaleza y sus cognados — salvaje, bárbaro y demás - son el antónimo del Proyecto de Civilización. El martillo geocultural de la dominación imperial tiene como prioridad hacer avanzar la tasa de ganancia contra las alianzas imperiales rivales (y a veces, desarrollistas) de capital-estado. El corazón de esta lucha es el proyecto imperial-burgués de perseguir y crear oportunidades de superbeneficio a través de la superexplotación (Amin, 2012; Smith, 2016; Lenin, 1963), una novedosa síntesis de explotación opresiva que enreda, como hemos visto, al Proletariado, al Biotariado y al Femitariado.

La naturaleza barata es una estrategia de superexplotación. Se trata de reducir los costes de re/producción a niveles inferiores a la media del sistema, una dinámica que da a las burguesías específicas una ventaja competitiva. El agente histórico-mundial de la superexplotación es la burguesía imperialista, una relación de intercambio político expresada en el geopoder imperial y la explotación de clase (Arrighi, 2010). Sus mecanismos son modos de dominación política y culturalmente forzados que operan a través de abstracciones dominantes de la naturaleza racializada y de género. Sus mecanismos geoculturales no sólo reducen la factura salarial de una capa significativa del nuevo (semi)proletariado (por ejemplo, las “brechas salariales” raciales y de género, así

\footnotetext{
27 "Los dominios metropolitanos de cada [hegemonía mundial] en esta secuencia abarcan un territorio más amplio y una mayor variedad de recursos que los de su predecesora"(Arrighi, 20I0:I4).A principios del siglo XIX, por ejemplo, “Gran Bretaña no sólo era un Estado-nación plenamente desarrollado y, como tal, una organización más grande y compleja de lo que nunca habían sido las Provincias Unidas; también estaba en proceso de conquistar un imperio comercial y territorial que abarcaba todo el mundo y que daba a sus grupos dirigentes y a su clase capitalista un dominio sin precedentes sobre los recursos humanos y naturales del mundo" (Arrighi, 2010: 223), énfasis añadido.

28 Para una concepción histórico-mundial de la sobreexplotación secuencial, véase Moore (2000).
} 
como la segmentación del mercado laboral) sino que también amplían la jornada laboral no remunerada —el "segundo turno"- e imponen el "subconsumo forzado" (Araghi, 2009). DuBois (I 999 , p. 15) llamó a esto "la última explotación" de la plantación proletaria, y unifica el agotamiento de los paisajes y los cuerpos trabajadores en tensión dialéctica. La larga historia de los "trabajadores desechables" en la feliz frase de Melissa Wright (2006) se extiende desde los campos de caña de la Bahía hasta las fábricas de Manchester y las maquiladoras del México neoliberal.

El Proletario Desechable es el eje de la Naturaleza Barata y el resultado de la superexplotación —antes como ahora, aunque nunca de la misma manera-. Marx anticipó el argumento en su exposición sobre la Jornada de Trabajo ¿Por qué, se pregunta Marx, el capitalista industrial "produce el agotamiento prematuro y la muerte de la fuerza de trabajo"? (Marx, 1967, p. 376). Por dos razones, respondió. La una era necesaria para la otra. Primero,"las leyes inmanentes de la producción capitalista se enfrentan al capitalista individual como una fuerza coercitiva externa a él” (Marx, 1967, p. 38I).Y, sin embargo, el agotamiento de la fuerza de trabajo sólo puede producirse en la medida en que puedan movilizarse nuevas fuentes de trabajo "físicamente incorruptas" (suministros latentes de fuerza de trabajo) (Marx, 1967, p. 256). Es la frontera -en condiciones de dominio imperial-burgués - la que contrarresta la tendencia al aumento de los costes de reproducción en las zonas centrales relativamente capitalizadas (Moore, 20I5a).

La gran mayoría del proletariado mundial en los siglos posteriores a 1492 estaba encerrado en la Natureza, siendo objeto del Proyecto Civilizador, del que surgieron nuevas estrategias, cada vez más modernas, de dominación racializada y de género. Hacer que estas estrategias sean primordiales - 0 independientes de la lucha de clases mundial- ignora las especificidades del racismo y el sexismo capitalista en la formación de clases y la superexplotación que posibilitó. La cosmología de la civilización y el salvajismo fue el latido del corazón de esa proletarización racializada y de género; es decir que, en definitiva, fue un instrumento de dominio de clase.

Elaborada a partir de 1492, vemos esa nueva cosmología en funcionamiento - y con ella, un conjunto práctico de supuestos y directrices originarios para los nuevos imperios marítimos- de Naturaleza, Civilización, Sociedad, Europa/eo que no son sólo abstracciones reales sino gobernantes, inventadas y reinventadas desde el largo siglo XVI (1450-1648) ${ }^{29}$. Lejos de ser una preocupación aislada de teólogos y filósofos, el proyecto civilizador se convirtió en una cuestión práctica de gobierno para las conquistas y las mercantilizaciones que siguieron. Quién y qué era civilizado, y quién y qué no era civilizado y, por tanto, natural, fue una cuestión que preocupó a soldados y sacerdotes, plantadores y propietarios de minas, banqueros y reyes, a lo largo de la larga duración del primer capitalismo.

La revolución ontológica del primer capitalismo, que creó límites cada vez más rígidos entre la civilización y la naturaleza, fue una revolución ideológica que precipitó las abstracciones dominantes. Éstas son los bloques de construcción de la ideología capitalista. Las abstracciones dominantes no son abstracciones del pensamiento que preceden a la acción concreta; son, más bien, los resultados de la praxis capitalista. El binarismo dominante original, la civilización y la natu-

\footnotetext{
29 El gran clásico sobre la abstracción real es el escrito por Sohn-Rethel (2020) que, sin embargo, aborda una dinámica de abstracciónformación real dentro de la ley capitalista del valor y las abstracciones producidas a través de sus momentos monetarios. Para entender la naturaleza como abstracción real, véase Moore (2017)
} 
raleza, se produjo activamente a través de la formación de clases supervisada por el imperialismo, su ethos de gestión planetaria y su alienación del trabajo mental y manual a escala mundial ${ }^{30}$. El surgimiento de estas abstracciones dominantes, a su vez, dio forma a la praxis capitalista, sobre todo a un Proyecto Civilizador notablemente flexible.

En esta praxis, la civilización y la naturaleza eran abstracciones tratadas como reales por los burgueses imperialistas y utilizadas prácticamente por las potencias territorialistas para crear buenos ambientes de negocios. Rápidamente se transformaron en los binarismos favorecidos por el naturalismo burgués del sexismo y el racismo mundial, pilares ideológicos de la superexplotación capitalista. El racismo y el sexismo naturalizados eran, en otras palabras, necesarios para extender la jornada laboral, imponer el subconsumo y apropiarse del trabajo no remunerado. Estas abstracciones dominantes - como la Humanidad y la Naturaleza actuales - describen el mundo para reproducir los negocios del capitalismo como siempre (o crear nuevas condiciones de rentabilidad.) Son, como subrayan Marx y Engels, "ideas dominantes" que invitan a la clase obrera a "compartir la ilusión de [su] época" —y, en la medida en que lo hacen, podemos hablar de abstracciones dominantes (Marx y Engels, 1976, p. 55)—.

Su raíz proviene de un naturalismo burgués que explica la opresión y la desigualdad $-y$, por tanto, la subordinación de las clases re/productoras- en términos de ley natural y no de relaciones de clase. Aunque hoy asociamos esto con el legado de Malthus y el eugenismo, sus raíces se remontan al instrumentalismo metafísico del primer imperialismo español (McNally, 1993; Robertson, 2012; Betancor, 2017). Entre el "conquisto, luego existo" de Colón y el "pienso, luego existo" de Descartes, se encontraba el proyecto cristianizador español. Su lema bien podría haber sido "conquisto, luego trabajo" pues la posición teológica emergente de principios del siglo XVI era el instrumentalismo metafísico, que sostenía que los españoles se situaban ante los pueblos indígenas del mismo modo que Dios se situaba ante los españoles cristianos (Betancor, 2017). El carácter "imperfecto" de los pueblos indígenas podría remediarse mediante el trabajo duro. El Arbeit macht frei proviene de los orígenes del capitalismo y su empuje genocida de superexplotación formado a través de la Gran Frontera.

Este era el Proyecto Civilizador, la lógica geocultural del nuevo imperialismo. Todas las fronteras de las mercancías fueron habilitadas por alguna variante de este Proyecto, cada una con inflexiones específicas de formación de clase racializada y de género, así como de dominio de clase. La antigua xenofobia fue desplazada progresivamente por una nueva lógica de dominación moderna, que enfrentaba a los civilizados con los salvajes. Cada nueva frontera mercantil fue habilitada por los imperios que "descubrieron" que los habitantes de la nueva tierra eran perezosos, irracionales o bárbaros (Alatas, 1977) (una de las razones por las que eslóganes como "ecosocialismo o barbarie" me dejan mal sabor de boca). La lógica geocultural era la de la "exclusión radical" a través de la cual los "cívicos" expropiaban las propiedades de los "salvajes" — los blancos de los negros, los hombres de las mujeres, los pensadores y gerentes de los trabajadores (Plumwood, 1993) - Las fronteras de las mercancías fueron de esta manera el caldo de cultivo de exclusiones radicales y de la formación del binarismo cartesiano como lógica cultural de superexplotación,

30 Esta afirmación está, por supuesto, influenciada por Sohn-Rethel (2020), cuya formulación se centra en la dinámica de la acumulación de capital propiamente dicha, mientras que la abstracción dominante pone de relieve la aparición de ideas dominantes tratadas como reales en la praxis capitalista a escala mundial.Ambas - abstracciones reales y dominantes- encuentran un terreno común en la producción ideológica del ethos empresarial basado en la alienación del trabajo mental y manual. 
que a su vez dio forma a una lógica de gestión de la racionalización del lugar de trabajo con su separación en varios niveles de trabajo mental y manual (Braverman, 1975).

Cada frontera de las mercancías produjo nuevas expresiones de lo civilizado y lo salvaje: los andinos del siglo XVII se convirtieron en naturales; los irlandeses del siglo XVI, en salvajes; los pueblos indígenas de las Carolinas de finales del siglo XVII vivían, según Locke, en un estado de naturaleza. Y en todas partes, los seres humanos que vivían, respiraban y residían en las nuevas fronteras eran despojados de su Humanidad, definida de diversas maneras como perezosa, no cristiana, no civilizada o no desarrollada (Patel y Moore, 2017). La frontera de las mercancías, parafraseando a Ynestra King (1989), era una zona de "sacrificio humano".

¿Qué puede decirnos la frontera de las mercancías sobre esta historia mundial? Nos orienta sobre cómo la lógica geocultural de dominación del capitalismo estaba explícita e íntimamente conectada con el impulso del capitalismo para convertir a los seres humanos y al resto de la naturaleza en oportunidades de obtener beneficios, y cómo ambos produjeron y fueron producidos por la creación de un entorno capitalista. Separar esta trinidad — poder, beneficio y vida - ha sido un logro del giro neoliberal en la academia, insistiendo en todas partes en estos fragmentos y sus particularidades. Pero en el terreno de la especificidad histórica real (pienso en las fronteras azucareras/esclavistas de Bahía y Barbados) no se produjo tal fractura. La dominación racista, la despiadada explotación de clase, el incesante afán de lucro, las extraordinarias deforestaciones... todo estaba enredado en una ecología-mundo capitalista que premiaba la aptitud competitiva y castigaba a los que no cumplían con la tasa de ganancia. Las fronteras eran lugares en los que las riquezas atraían, precisamente, porque las fronteras eran lugares en los que las posibilidades de resistencia efectiva eran más bajas, y las formas variadas de "fertilidad natural" (suelos, minerales, bosques, etc.) eran más altas.

Las fronteras eran zonas de la naturaleza cuyo "salvajismo" podía ser civilizado a través del trabajo. El propio trabajo fue redefinido de forma que favoreció la búsqueda de poder y la acumulación de capital. En ello, es conocido que el llamado trabajo de las mujeres fue redefinido como "natural”, o como "no trabajo" (Federici, 2004). La "Gran Domesticación" fue fundamental para la Gran Frontera (Patel y Moore, 2017). La racialización fue igualmente, aunque de forma diferenciada, indispensable para autorizar todo tipo de opresión para extraer trabajo remunerado y no remunerado ${ }^{31}$, especialmente después de 1550, cuando empezamos a ver las cristalizaciones decisivas de un nuevo modo totalmente diferente de las civilizaciones precapitalistas, de hacer frontera. Reconfiguradas como zona de salvajismo (naturaleza), las fronteras mercantiles se convirtieron en zonas de fuego libre para la acumulación militarizada.Así, a través del Proyecto Civilizador, la estrategia de la frontera mercantil

proporciona la base estructural de una tendencia similar al apartheid, una tendencia a tener al menos dos tipos de desarrollo muy diferentes y dos tipos diferentes de socialidad capitalista en el núcleo mismo del capitalismo explotador. Uno se define por una explotación civilizada, cosmopolita, regulada por el Estado, legal, apoyada por el bienestar y preocupada por la ecología. La otra está definida por un capitalismo salvaje y

31 Véase Moore "On the Origins of Climate Apartheid" disponible en https://www.youtube.com/watch?v=bV4uR8iO2-8 
anárquico, espacial o socialmente periférico al centro cosmopolita (esta lógica centro-periferia puede ser internacional o intranacional, incluso puede ser intraurbana entre dos formas de habitar socialmente la misma ciudad cosmopolita), y dominada por la explotación, el robo y el saqueo sin control. Uno está regulado con una lógica policial. El otro es un espacio de guerra (Hage, 2017, p. 60)

Esta estrategia "parecida al apartheid" era —como el régimen sudafricano- una estrategia desarrollista basada en la superexplotación. Se trataba de una política de clase; su racialización era fundamental tanto para "dividir y gobernar" como para "definir y gobernar" (Bond, 2007; Lotta, 1985; Mamdani, 2012) siendo también una estrategia imperialista, revelada por las ocupaciones e invasiones de Namibia y Angola durante décadas por parte de Sudáfrica. El apartheid sudafricano fue una estrategia de acumulación que prometía las riquezas del Desarrollo, que no era más que la reedición del Proyecto Civilizador después de 1949. Así, el vínculo entre "civilización" y "salvajismo" se reproduce a través de la acumulación mundial, sostenida a su vez por movimientos fronterizos basados en la lógica geopolítica y geocultural del Proyecto Civilizador. Esto es lo que yo llamo - para disgusto de mis camaradas brennerianos - un marxismo político a escala mundial (Moore, 2018a). Está en el corazón de la conversación sobre ecología-mundo, que insiste en que las relaciones del capitalismo con la Naturaleza (la abstracción dominante), la red de la vida y los oikeios (su pulso de creación de vida) están siempre culturalmente fundamentadas y políticamente mediadas.

¿Qué sucede cuando la lógica de superexplotación del capitalismo en la red de la vida se acerca al final de las fronteras que se abrieron en el gran arreglo climático del largo y frío siglo XVII? ¿Qué podemos esperar de la trinidad capitalogénica — la división de clases climáticas, el apartheid climático, el patriarcado climático- en la era del infierno planetario y el cierre total de los bienes comunes atmosféricos? A estas preguntas podemos dirigirnos ahora.

\section{La Gran Implosión. De la solución climática a la crisis climática}

Hoy en día, las mismas estrategias de poder, beneficio y vida que se encuentran detrás del arreglo climático del siglo XVII están impulsando la crisis climática, que es también geofísica, ya que marca el final del Holoceno, y geohistórica, pues se trata de una crisis epocal de la ecología-mundo capitalista. A menudo suelen separarse ambas facetas, analítica y políticamente. Pero es un error. Las condiciones climáticas son fundamentales para la sociedad de clases, y la sociedad de clases ha sido — ihasta hace poco! - fundamental para la estabilidad del Holoceno. De hecho, la estabilización del CO2 atmosférico en torno a 270-280 ppm hacia el año 4000 a.C. fue el producto de una revolución agrícola-urbana afroeuroasiática (Ruddiman, 2005; Childe, 195I). La sociedad de clases se convirtió en una palanca arquimédica de la estabilización del Holoceno, contrarrestando la tendencia a la descarbonización y a la renovación de la glaciación que caracterizó los diecinueve períodos interglaciares anteriores. El clima, en esta lectura, ciertamente no lo es todo. Pero es imposible explicar nada sobre la longue durée de la sociedad de clases sin él. 
El arreglo climático del siglo XVII, basado en la Gran Frontera, tropezó con una expresión muy moderna de esta dinámica. El impulso de la mano de obra barata, como hemos visto, magnificó los impactos de las enfermedades en las Américas más allá de lo que la humanidad había experimentado. La consiguiente descarbonización —el pico de Orbis (1610)— reforzó el "forzamiento natural" que impulsaba el peor clima de la Pequeña Edad de Hielo. Como hemos visto, las crisis financieras y fiscales se unieron a las guerras y al malestar político para obligar a los imperios europeos y a los capitalistas a dar un giro productivista, con repercusiones que sacudieron la tierra, y que se sintieron desde el Atlántico Sur hasta el sudeste asiático. Esta fue la revolución ecológico-mundial del largo y frío siglo XVII (Moore, 20I0c; 20I0d; 20I7c; 20I8a). Al igual que la revolución urbano-agrícola de unos 8.000 años antes, la solución climática del primer capitalismo fue una máquina de carbonización, aunque esta vez con esteroides. Su palanca arquimédica, desde el punto de vista organizativo, fue la revolución extractiva de las plantaciones. Su base de clase estableció una polaridad emergente de burguesías imperialistas (desgarradas por rivalidades geopolíticas) y el Proletariado Planetario, entendido como nuestra unidad diferenciada de Proletariado, Biotariado y Femitariado.Así tomó forma la trinidad capitalogénica: la división de clases, el patriarcado y el apartheid climáticos.

Esta trinidad fue fundamental para la solución climática del primer capitalismo y es ineludible en la crisis climática actual. No es el resultado — sino la causa- de la Gran Implosión actual.

La Gran Implosión es algo más que la "desaparición de la frontera” (Turner, 1921). Para enmendar la formulación clásica de Frederick Jackson Turner, estamos asistiendo no al "cierre" sino a la implosión- de "un gran movimiento histórico" (Turner, 1921). La transición geohistórica en curso es una inversión epocal de la relación definitoria del capitalismo con la red de la vida y dentro de ella. Se trata de la transición de la red de la vida como una dinámica de reducción de costes y aumento de la productividad a una dinámica de maximización de costes y reducción de la productividad. La clase dirigente y los economistas marxistas han entendido sus primeros signos como el Gran Estancamiento ${ }^{32}$, pero esto es sólo el principio, con lo que podríamos llamarlo una “crisis de señalización” (Arrighi, 20I0). El Gran Estancamiento señala los primeros momentos de la Gran Implosión.

La Gran Implosión es una inversión epocal del Gran Abaratamiento que inauguró la era capitalista. Al igual que el Gran Abaratamiento, la Gran Implosión es un acontecimiento no lineal en el que el capitalismo se ha convertido en un nuevo tipo de "fuerza geológica", parafraseando a Vernadsky. $Y$ es que conviene recordar que el capitalismo fue, desde el principio, una fuerza geológica. Su mayor logro en los dos siglos posteriores a 1492 fue la creación de una Pangea moderna, que unificó la vida planetaria por primera vez en 175 millones de años. Los críticos podrían objetar que esta Pangea moderna fue accidental, pero fue todo lo contrario. Las flotillas transoceánicas de armas, esclavos y capital no tenían precedentes en la historia de la sociedad de clases. La Gran Implosión de hoy es la transformación cantidad/calidad de esa Pangea moderna, un logro geohistórico que conduce en línea directa al "cambio de estado" de la biosfera, a la vez productor y producido por la crisis del capitalismo.

32 Habitualmente es denominado como "estancamiento secular", pero véase Cowen (20II). Roberts (20I6), lo denomina como la "larga depresión". 
Los científicos de los sistemas terrestres utilizan el concepto de "cambio de estado" para seguir los puntos de inflexión fundamentales — como el cambio climático- en la biosfera. Estos cambios de estado se producen "de forma abrupta e irreversible... cuando [los sistemas ecológicos] se ven forzados a cruzar umbrales críticos" (Barnosky et al., 2012; Steffen et al., 20I5). La incorporación de la no linealidad en el pensamiento biológico no es, por supuesto, nueva, y mantiene una relación polémica con el catastrofismo (Eldredge y Gould, 1972; McBrien, 2016), pero el principio de transformación cantidad/calidad es totalmente compatible con el pensamiento dialéctico ${ }^{33}$. A pesar de esto, la mayoría de los marxistas se han resistido a la idea de que los modos de producción están ontológicamente conectados a la red de la vida ${ }^{34}$. Esto ha dejado al materialismo histórico mal equipado para ver la dialéctica de la doble internalidad: el capitalismo en la red de vida y la red de vida en el capitalismo. A pesar del implacable énfasis de Marx en la interpenetración mutua de capital, clase y trabajo en la red de la vida - y la regla dialéctica de las relaciones intercambiables entre sujeto y objeto- los marxistas, en general, se abstienen de ver las redes de la vida como productos y productores variables de la sociedad de clases. El énfasis metodológico está ligado a una cuestión práctica: ¿De qué manera el "forzamiento del capital” no lineal del cambio climático induce el "forzamiento del clima" lineal de la crisis capitalista? En otras palabras, ¿cuál es la relación histórico-dialéctica de la "formación de la tierra" y la "formación social"?

La apertura y el cierre de la Gran Frontera nos llevan del Gran Abaratamiento a la Gran Implosión ¿Qué ocurre con la acumulación mundial una vez que comienza el cierre - $y$, por tanto, la implosión - de las fronteras? Para subrayar la cuestión con precisión: estamos ante la contracción del trabajo/energía no remunerados (los Cuatro Baratos) en relación con la masa creciente de capital que busca salidas de inversión rentables (Moore, 20I5a, 20l lb, 20l7a). El dinamismo capitalista crea más capital del que puede invertirse de forma rentable. Esto es una obviedad marxista. Aunque las formulaciones precisas varían, toda la economía política marxista lucha con una u otra versión del problema de la absorción del capital excedente. La principal contra-tendencia se deriva de la apertura de fronteras que entregan mano de obra barata, alimentos, energía y materias primas a un coste muy inferior al preexistente (de nuevo, entendido en términos de valor). La Gran Frontera es crucial para solucionar las crisis de sobreacumulación porque las sucesivas revoluciones industriales y sus "paisajes operativos" dependen de uno u otro producto primario estratégico: los fluitschips holandeses se ensamblaron con madera barata de Noruega; las fábricas textiles de Manchester, con algodón barato del sur de Estados Unidos; los modelos T de Henry Ford fueron rentables sólo gracias al petróleo barato ${ }^{35}$.

La Gran Implosión no significa que no existan en absoluto fronteras de la Naturaleza Barata, sólo que las fronteras que existen hoy en día (por ejemplo, la Amazonia) no pueden restaurar los Cuatro Baratos lo suficiente como para absorber el capital excedente.

33 La mejor introducción concisa sobre esta materia es la realizada por Ollman (1993)

34 La astuta observación realizada por Harvey $(1998 ; 327-28)$ a finales de los noventa sigue siendo relevante: "El marxismo ha compartido con gran parte de la ciencia social burguesa un aborrecimiento general de la idea de que la "naturaleza" pueda controlar, determinar o incluso limitar cualquier tipo de esfuerzo humano. Pero, al hacerlo, ha evitado cualquier visión fundacional de la naturaleza o ha recurrido a una retórica demasiado simplista sobre "la humanización de la naturaleza" respaldada por un materialismo dialéctico e histórico que de alguna manera absorbió el problema apelando a un conjunto de principios ontológicos y epistemológicos... La respuesta de la izquierda a las crecientes preocupaciones ecológicas ha sido rechazar la política ambiental/ecológica como una distracción burguesa (como, de hecho, gran parte de ella lo es) o hacer concesiones parciales a la retórica ambiental y tratar de reconstruir el marxismo/socialismo sobre bases teóricas y prácticas bastante diferentes de las que tradicionalmente se han elegido como fundamento de la política de la clase obrera"

35 Para la historia de la naturaleza barata y las industrializaciones véase Moore (20I5); Patel y Moore (20I7); Brenner (20I9); Katsikis (20I6) y; Brenner, y Katsikis (2020) 
No cabe duda de que hoy existe un problema de capital excedente muy inflado lo que es a la vez síntoma y causa del Gran Estancamiento de la ganancia y la productividad, al que ahora nos referiremos.

\section{I El gran estancamiento de los beneficios y la productividad: Preludio de la Gran Implosión}

El Gran Estancamiento es el agotamiento de la Naturaleza Barata. Los signos de ello se encuentran por todas partes, pero tres son expresivos, y giran en torno al capital sobreacumulado y a la vacilante productividad del trabajo. Prefiguran contracciones dramáticas en el horizonte. El primero es el declive secular de la rentabilidad. La tasa de ganancia mundial lleva cayendo desde la década de 1870, contrarrestada temporalmente en varias coyunturas, especialmente entre 1947 y 1966 , y de nuevo entre 1983 y 2003 (Roberts, 2016; Maito, 2018; Carchedi y Roberts, 2013). La masa de capital acumulado sigue creciendo sin una expansión correspondiente de las oportunidades de inversión rentable. El giro es hacia un tipo de capitalismo rentista cada vez más -necesariamente- dependiente del poder del estado para asegurar su reproducción (Christophers, 2020). Los capitalistas "buscan inversiones improductivas, como la propiedad, para sustituir la inversión en la producción cuando la rentabilidad de los activos productivos cae" (Roberts, 2016, p. 226). Un indicador de la enormidad de ese capital sobreacumulado se encuentra en los informes de 2019 que identifican 17 billones de dólares en bonos del estado con "rendimientos por debajo de cero"36. Mientras tanto, la inversión inmobiliaria capitalista —-"propiedad poseída con el propósito expreso de lograr rendimientos de inversión"- se disparó creciendo un $50 \%$ entre 2013 y 2019, cuando alcanzó los 9,8 billones de dólares ${ }^{37}$. Las corporaciones financieras estadounidenses, cuya creciente participación en los beneficios empresariales definió el capitalismo neoliberal euroamericano, vieron cómo esa participación disminuía bruscamente después de 2002 y luego se estancaba (Skarstein, 20I I). La inversión no financiera en EE. UU. - y en todo el centro mundialcolapsó a principios de la década de 2000 y aún no se ha recuperado ${ }^{38}$ (Roberts, 2016). China, cuyo agresivo keynesianismo en medio de la Gran Recesión (c. 2008-10) "rescató" al capitalismo mundial (Harvey, 2018), es, por supuesto, una contratendencia. Pero no hay que exagerar.También en China han aumentado los costes laborales $y$, con ellos, la composición orgánica del capital.Tras un aumento momentáneo durante la Gran Recesión, la rentabilidad ha caído y se mantiene muy por debajo de los niveles anteriores a $2008^{39}$. Esto explica sin duda en cierta medida la inteligente estrategia de adquisición de recursos de China. A falta de vastas fronteras de naturaleza barata - suficientes para reanimar la tasa de beneficio mundial-, China no parece dispuesta a conducir

\footnotetext{
36 Los rendimientos de los bonos se han reactivado modestamente desde el "histórico" endeudamiento de los gobiernos, alcanzando los 15 billones de dólares en 2020, véase Marc Jones, "Rising yields still ‘a world away' from impacting sovereign ratings - S\&P Global”, yahoo!finance (3 de marzo, 202I), https://finance.yahoo.com/news/rising-yields-still-world-away-I807I5448.html ; también Joy Wiltermuth,

"That near-\$1 7 trillion pile of negative-yielding global debt? It's a cash cow for some bond investors", MarketWatch (22 de agosto de 20I9), https:// www.marketwatch.com/story/that-near I 7-trillion-pile-of-negative-yielding-global-debt-its-a-cash-cow-for-some-bond-investors-20।9-08-22 Adam Haigh, "The World Now Has \$13 Trillion of Debt With Below-Zero Yields", Bloomberg.com (20 de junio de 2019 ), https://www. bloomberg.com/news/articles/2019-06-2I/the-world-now-has-I3-trillion-of-debt-with-below-zero-yields

37 Véase Kyle Campbell,“Growth of the \$9trn Global Real Estate Market in Six Charts,” PERE News (27 July, 2020), https://www.perenews.com/ the-growth-of-the-9trn-global-real-estate-market-in-six-charts/.

38 Véase Rex Nutting, "Shareholder primacy is ruining America," MarketWatch (22 Mayo, 2019), https://www.marketwatch.com/story/capitalismis-failing-america-says-a-conservative-republican-2019-05-20 ; Michael Roberts, “The Debt Dilemma," The Next Recession (I0 May, 2020), https://thenextrecession.wordpress.com/2020/05//0/the-debt-dilemma/

39 Véase Editores, "Measuring the Profitability of Chinese Industry," Chuăng (2I Junio, 2020), https://chuangcn.org/2020/06/measuringprofitability/
} 
el capitalismo hacia una nueva edad de oro.

Nuestros dos siguientes indicadores de la Gran Implosión giran en torno a lo que suele llamarse la "base real" de la acumulación de capital: la productividad del trabajo. Podemos destacar dos formas principales de productividad laboral. Una de ellas es la agricultura, y está relacionada con la cuestión de los alimentos baratos, que a su vez influye decisivamente en el coste de la fuerza de trabajo. La segunda se refiere a los llamados sectores "secundario" y "terciario".

En el corazón de la agricultura capitalista, el crecimiento de la productividad ha disminuido drásticamente desde los años ochenta. En la agricultura estadounidense, el crecimiento de la productividad del trabajo en las últimas cuatro décadas ha disminuido en más de un tercio en relación con la media de la posguerra (1948-1980/I98I-2014); en la Unión Europea, el crecimiento de la productividad del trabajo agrícola luchó por alcanzar el uno por ciento anual en la década de 2010 (Fuglie et al., 2007; Eurostat, 2019). El crecimiento del rendimiento estadounidense en cultivos básicos tan importantes como el maíz y el trigo cayó bruscamente en la década de 2000 con respecto a la media de la posguerra. En relación con el período 1936-90, el crecimiento del rendimiento del maíz estadounidense cayó un 39\% y el del trigo, un 70\% (Andersen et al., 2018, p. 1085). En el caso del trigo indio, en el centro de la Revolución Verde, el crecimiento del rendimiento se desplomó en el mismo periodo, pasando del 3,4\% anual en la década de 1980 a sólo el 0,6\% en la de 1990 (Matuschke y Qaim, 2007).

El cambio climático explica un incremento crítico de esta caída de la agricultura. Existe un amplio consenso entre los investigadores de que la agricultura se ha vuelto más - no menos- "sensible al clima" (Ortíz-Bobea et al., 2018). Es una descripción bastante anodina con implicaciones fundamentales para el capitalismo pues recordemos que este se basa en un modelo sencillo: producir cada vez más alimentos con menos fuerza de trabajo. Hasta ahora, el modelo está funcionando, aunque más lentamente que antes. Pero la crisis climática presagia un cambio de época (Moore, 20I0e y 20I5d).

Un aleccionador informe de 2017 considera que el cambio climático hará retroceder la productividad agrícola a "niveles anteriores a 1980 en 2050, incluso teniendo en cuenta las tasas actuales de innovación" (Liang et al., 2017). Tampoco debemos imaginar que la supresión de la productividad agrícola por parte del clima es meramente especulativa. En 2008, la producción mundial de maíz y sus derivados eran un 3,8 por ciento y un 5,5 por ciento, respectivamente, menores de lo que habrían sido en un mundo sin cambio climático (Lobell et al., 20 I I). Para 202I, el cambio climático capitalogénico habrá sido responsable de una "pérdida de los últimos 7 años de crecimiento de la productividad" (Ortíz-Bobea et al., 2021, p. 309). En otras palabras, si no fuera por el cambio climático, los aumentos de productividad logrados en 2020 se habrían alcanzado en 2013. Como todo lo relacionado con el cambio climático, la media global oculta una considerable desigualdad. Mientras que el cambio climático suprimió el crecimiento de la productividad mundial en un $20 \%$ desde 196I, esa cifra fue un $30 \%$ mayor para el Caribe y un enorme $70 \%$ mayor para el África subsahariana (Ortíz-Bobea et al., 2021, p. 310).

Si el cambio climático está suprimiendo la productividad del Biotariado, también lo está haciendo con la del Proletariado. Una investigación realizada en 2019 por la OIT descubrió que el 
aumento del estrés térmico "es un problema grave para una gran proporción de los mil millones de trabajadores agrícolas del mundo" (OIT, 2019, p. 3) ${ }^{40}$.A medida que el estrés por calor se intensifica, para 2030, se proyecta que el 2,2 por ciento del "total de horas de trabajo en todo el mundo se perderá cada año, ya sea porque hace demasiado calor para trabajar o porque los trabajadores tienen que trabajar a un ritmo más lento." Obviamente, esas pérdidas proyectadas aumentarán de forma no lineal, a medida que el estrés térmico y otros momentos del cambio climático se intensifiquen, también de forma no lineal. En regiones como el sur de Asia y África occidental, subraya la OIT $(2019$, p. 3), las pérdidas de productividad serán más del doble de la media mundial (Zander et al. 20I5).Visto así, no es de extrañar que, para 2030, la agricultura mundial soporte un tercio de los costes globales derivados del cambio climático,y dos tercios para 2060 (Braconier et al., 20 I4).

Por último, desde principios de la década de 1970, el crecimiento de la productividad laboral en la industria y los servicios también se ha ralentizado drásticamente. En Estados Unidos, la productividad laboral se disparó entre 1920 y 1970, avanzando a un ritmo anual del 2,84\%. Entre 1970 y 2014 , esa tasa se redujo en más de un tercio, hasta el I,62\%. Robert Gordon (2016) prevé un descenso continuado, hasta sólo un I,2\% anual de aquí a 2040, aunque puede incluso ser optimista. En el sector manufacturero estadounidense, la productividad laboral -la producción real por hora- "fue menor en 2017 que en su pico de 2010". Benanav (2019, p. 19) prevé descensos comparables, incluso más dramáticos, para Francia y Alemania: el crecimiento de la productividad de este último país se desplomó del 6,3 por ciento en las décadas de 1950 y 1960, a sólo el 2,4 por ciento después de 2000. El crecimiento de la productividad del sector de los servicios sigue siendo más débil y, en la mayor parte del Sur Global, probablemente negativo. Ni siquiera el espectacular crecimiento de la productividad laboral de China —un 7,2\% anual entre 1993 y 20I3- compensa la tendencia sistémica (OIT, 20I4, p. 52). La productividad laboral en el Norte Global sigue siendo cuatro veces mayor, y los avances de China en cuanto a su productividad se han visto contrarrestados por el aumento de los costes laborales unitarios: un $85 \%$ entre 2000 y 201 I (Midnight Notes Collective, 2009, p. 4) ${ }^{41}$.

La paradoja, por supuesto, es que "las tasas de crecimiento de la productividad en el sector manufacturero se desplomaron precisamente cuando se suponía que estaban aumentando rápidamente debido a la automatización industrial" (Benanav, 2019, p. 19). Podría decirse que el mayor no acontecimiento de la era neoliberal es la no aparición de una nueva "revolución industrial" basada en la automatización y su promesa de avances significativos en la productividad (Moore, 2015a). En los años setenta, críticos sociales tan diversos en su política como Alvin Toffler (1984) y Ernest Mandel (1999) anticiparon sin aliento un mundo automatizado, pero nunca llegó. Esa no aparición tiene que ver con el cierre de la Gran Frontera y el correspondiente agotamiento de la Naturaleza Barata. En pocas palabras, las revoluciones tecnológicas del capitalismo iniciadoras de época están condicionadas geográficamente por las apropiaciones de las fronteras. La revolución de las TIC, aunque aparenta erigirse como un momento de prodigioso avance tecnológico, ha tenido poco impacto en el crecimiento de la productividad del trabajo. Ni la tecnología "de alta

\footnotetext{
40 Un relato brillante - aunque desgarrador - sobre trabajo agrícola, estrés térmico y devastación de la salud de los trabajadores se ofrece en Nading,"The Heat of Work: Dissipation, Solidarity, and Kidney Disease in Nicaragua”, en Sarah Besky y Alex Blanchette, editores, How Nature Works: Rethinking Labor on a Troubled Planet (Santa Fe, NM: University of New Mexico Press, 2019), 97-II4.

41 Véanse también los datos del Departamento Estadounidense de Comercio en su herramienta "Assess Costs Everywhere" disponible en https://acetool.commerce.gov/
} 
tecnología" ni la "verde" han invertido la tendencia a la baja ${ }^{42}$. En los años setenta, se prometieron fábricas robotizadas; en cambio, el capital creó el "taller de trabajo global”.

\subsection{La Gran Implosión: De la acumulación de capital a la activación del valor negativo}

El abaratamiento y la devaluación no lineales del Proletariado, el Biotariado y el Femitariado que permitieron la supervivencia del capitalismo en el siglo XVII están activando hoy su negación no lineal. Se trata de la movilización del valor negativo: relaciones que inicialmente se vuelven resistentes, y luego intratables, frente a los negocios habituales del capitalismo (Moore, 2015a; Otero y Lapegna, 2016; Graham, 2017; De Loughry, 2019). Mientras que el pensamiento de los "límites del crecimiento" privilegia las sustancias, la crítica dialéctica pone el acento en las relaciones que envuelven a las sustancias, que a su vez condicionan materialmente las relaciones. Las caras del valor negativo son múltiples: abarcan todo, desde las supermalezas hasta la proliferación de movimientos de "justicia” (alimentaria, climática, energética, etc.), pasando por el cambio climático. No se pueden "arreglar" de la forma en que se estableció por primera vez el largo y frío siglo XVII. De hecho, a pesar de que se diga lo contrario, cuanto más se cierra la Gran Frontera, mayores son la desesperación y la fuerza tanto de la división de clases climáticas, como del apartheid y el patriarcado climáticos. La Gran Implosión es también una Gran Involución: las contradicciones del capital se repliegan sobre sí mismas, dando lugar a un ataque sin precedentes de toxificación y violencia. La razón de que esto sea así es sencilla: los negocios del capitalismo, como siempre, es decir, su conjunto de innovación técnica, acumulación militarizada y Naturaleza Barata fluyeron a través de la Gran Frontera. Esos sucesivos movimientos fronterizos permitieron a las burguesías imperiales frenar la tendencia al aumento de los costes de producción en el sentido de Marx, y contener las clases peligrosas puestas en marcha por la industrialización y la superexplotación imperialista. Su cierre representa un punto de inflexión cantidad-calidad: una crisis epocal del capitalismo.

La Gran Implosión está estrechamente conectada con el mayor movimiento fronterizo del siglo XX: el cercamiento de los bienes comunes atmosféricos como vertedero de las emisiones de gases de efecto invernadero del capital. Lo que Andreas Malm (2016) denomina "capital fósil" es uno de los vectores de este cercamiento, que a su vez es un producto del arreglo climático del siglo XVII. Las revoluciones extractivas de la turba y el carbón de esa época coincidieron con el giro productivista de la Gran Frontera después de 1550, fundamental para la proletarización y el avance de las fuerzas productivas.

Las fronteras adoptan múltiples formas geográficas: terrestres, subterráneas, marítimas, atmosféricas, jincluso los cuerpos humanos! No siempre tienen que ver con la producción directa: la acumulación primitiva de género que convirtió a las mujeres en las "salvajes de Europa" (Federici, 2004) es un ejemplo de ello. La proletarización requirió la feminización como condición dialéctica. Las burguesías tenían que asegurarse el "monopolio" de las fuerzas de reproducción como condición para la proletarización de las masas y la extensión de las condiciones fabriles en Europa (Barca, 2020). Podría decirse que este fue el punto de inflexión de un naturalismo burgués —redefiniendo, por motivos biológicos, la actividad de la mujer como "no trabajo" (Federici, 2004, p. 92; von Werlohf, 1988)—.A partir de 1492, la acumulación primitiva formó, fusionó y diferenció

42 Sobre el antagonismo entre la "tecnología limpia" y la búsqueda de rentas neoliberales, véase la importante obra de Jesse L. Goldstein (2018). 
el Femitariado y el Biotariado a través del crisol geocultural de la Naturaleza — que a su vez se desarrolló a través del crisol geográfico de la Gran Frontera-. Esta fue la abstracción dominante que legitimó la subordinación de los reproductores directos de trabajo y energía socialmente necesarios, aunque no remunerados. No reducibles, pero dialécticamente unidos, el Femitariado y el Biotariado produjeron las condiciones de la proletarización expandida y el circuito del capital. La "cuestión sexual" de la Gran Domesticación era una "cuestión general de clase" (von Werlhof, 1988, pp. 102-103).

Cabe decir que el avance de la frontera de los residuos también lo fue. Un rasgo distintivo del neoliberalismo ha sido encerrar completamente no sólo los cielos, sino también nuestros cuerpos, ahora movilizados como vertederos ambulantes de residuos tóxicos para la contaminación capitalista y causantes de todo tipo de cánceres, trastornos autoinmunes y, ominosamente, el colapso de la fertilidad. Esto último revela una configuración diferente del Biotariado y Femitariado en la Gran Implosión. La fertilidad mundial se redujo en un $50 \%$ entre 1960 y 2015 por muchas razones, incluyendo lo que The Economist llamó una "huelga de bebés" por parte de las trabajadoras profesionales (Swan y Colino, 202I). Pero una parte cada vez mayor de ese descenso está, en opinión de Shanna Swann, impulsado por los plásticos y otros tipos de contaminación, lo que provoca el aumento de las tasas de abortos espontáneos y el descenso del número de espermatozoides. Tan grave es esto último que el recuento de espermatozoides entre los hombres de los "países occidentales" — la fertilidad masculina es, al parecer, más sencilla de medir- ha caído más de la mitad desde finales de los años setenta. Se espera así que, para 2045, "tendremos un recuento medio de esperma igual a cero”43. La demografía se une a la Gran Implosión.

La Gran Implosión pone en entredicho las ortodoxias establecidas. En un ejemplo sorprendente del poder de las Dos Culturas y de la disonancia cognitiva que produce, esa no-linealidad ha sido - hasta ahora - encerrada dentro de la abstracción dominante: la Naturaleza. De ahí el impulso del catastrofismo ecomarxista: el capitalismo sobrevivirá "hasta que se corte el último árbol” (Bellamy Foster, 2013, p. 206; Moore, 2017a). Esto exagera drásticamente la resistencia del capitalismo. Pensar que el capitalismo puede sobrevivir al final del Holoceno y reestructurarse en medio de una inestabilidad climática extraordinaria es, verdaderamente, dotar al capitalismo de poderes sobrenaturales.

Dejando de lado el pensamiento mágico, son muchos los factores que sustentan la fe radical en la resistencia del capitalismo. El más importante es la incapacidad de reconocer el capitalismo como un sistema de acumulación, dominio y lucha de clases basado en la Gran Frontera que ya expuso Webb en 1952.Aunque muchas de sus formulaciones específicas eran parciales, incluso incorrectas, el concepto iluminaba algo fundamental sobre lo que él llamaba el "boom fronterizo" del capitalismo (Webb, 1954). Esta gran expansión económica de los siglos comprendidos entre I 492 y I9|4 no fue el resultado de la superioridad tecnológica, civilizatoria o política de Europa. Fue más bien el resultado de grandes expansiones territoriales que proporcionaron "beneficios inesperados" a una escala inimaginable. Estos beneficios inesperados fueron momentos de época del Gran Abaratamiento. Webb no negó que se produjeran innovaciones tecnológicas, civilizato-

\footnotetext{
43 Véase la entrevista realizada por Corbyn a Swan para The Guardian, el 28 de marzo de 202I, titulada "Interview: Shanna Swan: Most couples may have to use assisted reproduction by 2045 '. Disponible en https://www.theguardian.com/society/202I/mar/28/shanna-swan-fertilityreproduction-count-down
} 
rias o políticas; argumentó que las ganancias inesperadas hicieron posible estas innovaciones. Desde este punto de vista, el capitalismo no se formó dentro de una Europa reificada, sino que surgió en y a través de la Gran Frontera. Fue, no hace falta decirlo, un movimiento sangriento a través del cual la riqueza económica creció y el poder político se justificó en nombre de los proyectos civilizadores. Olvidamos con demasiada facilidad que las fronteras siempre fueron creadas y conquistadas por soldados con armas, sacerdotes con Biblias y contables con libros de contabilidad (Patel y Moore, 2017).

Hoy en día, la implosión de la Gran Frontera viene ampliamente entendida en su faceta geofísica, la del Antropoceno geológico, pero esa comprensión es indirecta pese a la avalancha de investigaciones extraordinarias producidas en todas las ciencias del sistema terrestre. Sin embargo, desde el punto de vista geohistórico, la Gran Implosión no se comprende correctamente, incluso para la minoría que quiere hablar del capitalismo y del Capitaloceno. La inversión epocal que subrayé al principio de la tercera sección implica no sólo una transición que se aleja de la red de la vida como oportunidad para obtener beneficios, sino una transición hacia una resistencia epocal al impulso prometeico del capitalismo. El "ciclo de domesticación" a través del cual el capital, el imperio y la ciencia realizaron el control sobre esferas limitadas de la vida está llegando a su fin (Wallis, 2000). Las supermalezas, las superplagas y las superenfermedades están alterando las geografías del capitalismo y de la vida cotidiana de una manera que está frustrando las disciplinas del capital. Esto está desestabilizando el cálculo de beneficios de la acumulación mundial tal y como lo hemos conocido durante cinco siglos. El Gran Estancamiento es lo que ocurre cuando una civilización preparada para la acumulación y la expansión geográfica sin fin se enfrentan a una realidad biosférica que no coopera. Llámese "la rebelión del Biotariado".

¿Seguirán otras capas del Proletariado Planetario esta lógica? Volvemos al problema de la bola de cristal. Ni la predicción ni la retrodicción ofrecen respuestas fáciles. Pero, sin duda, la crítica inmanente del capitalismo en la red de la vida, que gira en torno a la expansión y la implosión en curso de las Grandes Fronteras, constituye un punto de partida necesario. Poner en primer plano la dialéctica de la lucha de clases dentro de la movilización planetaria del capitalismo de Biotariado, Femitariado y Proletariado abre un medio para mantener el diálogo — iy la praxis? - en torno a la justicia planetaria al final de la Gran Frontera.

\section{Conclusión: ¿revuelta del proletariado planetario? La lucha de clases mundial en la red de la vida}

El capitalismo está cerrando el telón a esa larga era de inusual estabilidad climática que llamamos Holoceno. Son malas noticias para todos nosotros. Sin embargo, los últimos cuatro milenios de historia climática y sociedad de clases también señalan algo esperanzador: el dramático cambio climático es el gran desestabilizador del dominio de clase.

Históricamente, los cambios climáticos drásticamente desfavorables han hecho saltar por los aires aquellos límites de asentamiento y dominio bien establecidos, alterando el carácter de las fronteras imperantes. La crisis epocal del Occidente romano a partir del año 376 ilustra esta pauta. El ascenso de Roma estuvo respaldado por unas condiciones climáticas tan favorables que 
los historiadores lo llaman el "Óptimo Climático Romano". Cuando llegó a su fin en algún momento de finales del siglo II, las contradicciones del Imperio se profundizaron. Sobrevino entonces la "crisis del tercer siglo" de la guerra civil, enredada con el resurgimiento de la enfermedad, la peste cipriana, que vino acompañada de sorprendentes derrotas militares. En el año 25I, el rey godo Cniva destruyó las legiones romanas dirigidas por el emperador Decio en Abritus, en la actual Bulgaria. Toda la frontera romana desde el Rin hasta el Danubio “implosionó" (Harper, 2017).

El orden, por supuesto, fue restablecido, pero estos hechos fueron la señal de aviso de la inminente crisis epocal que se avecinaba. A partir del año 330, la estepa euroasiática sufrió una de las sequías más graves de los últimos 2.000 años y que persistiría durante las cuatro décadas siguientes (Holt, 20 I I; McCormick et al., 20I2). Esto amplió una conexión anterior entre la sequía y la migración ${ }^{44}$ (Drake, 20I7; Holt, 20I I; McCormick et al. 20I2).

La gravedad de la sequía del siglo IV contribuyó al audaz empuje hacia el oeste de los pueblos hunos, que a su vez expulsaron a los godos a través del Danubio en el año 376. Lo que comenzó como un paso fronterizo convencional y regulado se convirtió rápidamente en un conflicto abierto, provocado por las artimañas y el lucro de los romanos. El cronista Ammianus cuenta que los romanos vendían carne de perro a los godos a cambio de sus hijos. Otros cronistas "lamentaron el frenesí de los comandantes romanos que se apresuraban a adquirir esclavos sexuales [godos] y trabajadores agrícolas a bajo precio" (De Ste. Croix, I98I, p. 258). La migración climática, entonces como ahora, era una lucha de clases. Ese comportamiento era el "negocio habitual" de los romanos. Sin embargo, esta vez les salió el tiro por la culata.

Los godos del otro lado del Danubio se rebelaron y rápidamente se les unieron los comandantes militares godos al servicio de Roma, que se amotinaron y tomaron la armería de Adrianópolis. Por último, elementos clave del proletariado godo - especialmente los minerostambién se sublevaron, dando pie a lo que hoy llamaríamos una huelga general armada (De Ste. Croix, 198I). Al enfrentarse a las temibles legiones romanas en Adrianópolis en 378, los godos destruyeron el ejército imperial y quemaron vivo al emperador Valente. Desde Aníbal en Cannae en el 216 a.C., Roma no había sufrido una pérdida tan devastadora, sólo que entonces no se restableció el orden ni la seguridad de las fronteras, al menos en Occidente. Las migraciones bárbaras hacia el centro-oeste de Europa se vieron complementadas por los campesinos intranquilos - los Bagaudae - en España y especialmente en la Galia. Estas rebeliones, que se gestaron a partir de la crisis del siglo III, "alcanzaron tal clímax en la primera mitad del siglo V que fueron casi continuas" (Thompson, 1952, p. 20). En este punto, la propia Roma fue saqueada por las fuerzas visigodas en el año 4I0. Las puertas de la Ciudad Eterna no habían sido traspasadas desde Brennus en el 387 a.C., antes del inicio del Óptimo Climático Romano. Finalmente, los vándalos conquistaron Cartago en el 439, rompiendo la espalda del estado fiscal romano y asestándole así un golpe mortal (Wickham, 2006).

La historia climática, de clase y de crisis epocal fue dramática, pero no excepcional. Lo que merece la atención es el vínculo entre los cambios climáticos desfavorables y la crisis civilizatoria. Y bien digo "Crisis", no "colapso", pues este se refiere a un discurso neomaltusiano que combina

44 Sobre los acontecimientos que condujeron a la batalla de Adrianópolis en 378 véase Halsall (2007). 
argumentos poblacionales con un imaginario apocalíptico ${ }^{45}$. Lo que ocurrió en la crisis del Occidente romano, y de nuevo durante la crisis del feudalismo, no fue ni una pesadilla malthusiana ni neohobbesiana. En ambos casos, siguió una "edad oscura" — para las clases dominantes—, en cambio, para las clases productoras, las secuelas de la crisis epocal fueron algo así como una edad de oro. Qué fácil es olvidar —en un momento en que la izquierda promueve eslóganes como "ecosocialismo o barbarie" (Löwy, 20I5)— que las invasiones "bárbaras" contribuyeron poderosamente a la destrucción de la mayor sociedad esclavista que el mundo había conocido ${ }^{46}$ (y qué fácil es olvidar que dicho eslogan debe más a la filosofía política autoritaria de Hobbes que al socialismo revolucionario de Marx). Entre los siglos $\mathrm{V}$ y VII, un campesinado más o menos igualitario -Wickham (2006, pp. 535-547) lo llama "modo de producción campesino"- reorganizó el poder, los asentamientos y la vida en toda Europa centro-occidental. Las villas de los oligarcas fueron ocupadas y reutilizadas, y su centralidad en el campo fue rápidamente desplazada por una nueva forma de asentamiento: la aldea ${ }^{47}$ (Wickham, 2006, pp. 473-48I). El igualitarismo campesino coincidió, sin duda, con una reducción de la "complejidad social”, tomando prestada una frase de los colapsólogos (Diamond, 2005) (la complejidad social es más o menos un eufemismo para referirse a la sociedad de clases). Liberados de los oligarcas romanos - la tiranía del grano y otros cultivos comerciales - los campesinos siguieron estrategias de subsistencia creativas y diversas ${ }^{48}$. Como consecuencia, gozaron de mejor salud que sus predecesores de la época romana (Koepke y Baten, 2008). Tampoco se produjo un colapso de la población ${ }^{49}$ sino que, por el contrario, se produjo un prolongado declive que no se invirtió hasta finales del sigloVII en Francia y más tarde en otras regiones, lo que se corresponde con los primeros movimientos tentativos hacia un modo de producción feudal y el descongelamiento de la Pequeña Edad de Hielo de la Antigüedad Tardía hacia el año 650. De hecho, el colapso de la estructura de clases romana en la Antigüedad tardía se correspondió aproximadamente con un movimiento hacia la relativa igualdad de género ${ }^{50}$ (French, 2008; Halsall, 1995). Dado que las mujeres gozaron de una libertad comparativamente mayor para regular la fertilidad en ausencia de una regla de clase, los campesinos ajustaron sus regímenes demográficos a las condiciones climáticas del período frío de la Edad Media.

Una historia similar tuvo lugar durante la crisis climática del feudalismo (Federici, 2004; Seccombe, 1995). Mientras que la Gran Hambruna (1315-22) y la Peste Negra (1347-53) se vivieron como un acontecimiento milenario, la crisis feudal no fue en realidad "el fin del mundo", sino la crisis de un tipo particular de sociedad de clases. Como vimos en la primera parte, la apertura de la Gran Frontera fue una reorientación estratégica consciente de las capas dominantes de

\footnotetext{
45 La versión más popular de la tesis del colapso es la expuesta por Jared Diamond (2005) aunque su exponente más sofisticado es Joseph Tainter (1990).

46 "Cinco siglos, tres continentes, decenas de millones de almas: la esclavitud romana es el verdadero antecedente antiguo de los sistemas de esclavitud masiva del Nuevo Mundo... Una población de esclavos del orden de 5 millones de almas habría requerido cientos de miles de nuevos cuerpos al año para mantener los niveles de reposición. La reproducción natural era la principal fuente de nuevos esclavos, pero la exposición de niños, la autoventa, el secuestro y la importación transfronteriza eran importantes complementos” (Harper, 20I I: 3”.

47 La investigación de Tamara Lewit (2005) sobre la ocupación campesina y la reutilización de las villas es extraordinaria.Véase, entre otros, Lewit, "Bones in the Bathhouse: Re-evaluating the Notion of 'Squatter Occupation' in 5th-7th Century Villas", en Gian Pietro Brogiolo, Alexandra Chavarría Arnau, Marco Valenti, eds., Dopo la fine delle ville: le campagne dal VI al IX secolo (Mantova, 2005$), 25$ I-62.

48 Sobre la creatividad agroecológica del campesinado, véase Lewit (2009) y Innes (2007), "Pigs, presses and pastoralism: farming in the fifth to sixth centuries AD”, Early Medieval Europe 17(I, 2009), 77-9I, citas: 83, 77; Matthew Innes, Introduction to Early Medieval Europe, 300-900: The Sword, The Plough and the Book (Nueva York: Routledge, 2007), 449.

49 Aunque la peste de Justiniano (c. 54|-549) tuvo consecuencias, la descomercialización de la época permitió a los campesinos de fuera del litoral mediterráneo cierta protección epidemiológica.

50 Sin duda, las formaciones campesinas medievales tempranas difícilmente constituían un paraíso feminista, véase Wickham (2006: 554-557).
} 
Europa, que habían perdido la lucha de clases en la campiña europea occidental ${ }^{51}$. Lo que ocurrió como resultado fue, al igual que la crisis epocal del Occidente romano mil años antes, una edad de oro para los trabajadores y los campesinos. El siglo y medio que siguió a la Peste Negra puede haber sido una edad oscura para los gobernantes, pero para todos los demás fue una edad de oro. Durante dos siglos después de la Peste Negra, como observa Braudel, las clases productoras experimentaron un "nivel de vida extremadamente favorable":

Los salarios reales nunca habían sido tan altos como entonces. En I388, los canónigos de Normandía se quejaban de que no encontraban a nadie para cultivar sus tierras "que no exigiera más de lo que se hubiera pagado a seis criados a principios de siglo". Hay que subrayar la paradoja, ya que a menudo se piensa que la penuria aumenta cuanto más se retrocede hacia la Edad Media. En realidad, ocurre lo contrario con el nivel de vida del pueblo llano - la mayoría-. Antes de I52040 , los campesinos y artesanos del Languedoc (todavía poco poblado) comían pan blanco, un detalle revelador. Pero con el paso del tiempo, tras el "ocaso" de la Edad Media, el deterioro se agravó progresivamente, prolongándose hasta bien entrado el siglo XIX (Braudel, 198, pp. 193-194)52.

La retrodicción y la predicción están unidas dialécticamente. El pasado no es un prólogo. Pero tampoco ha terminado. Uno se pregunta, con razón, si la crisis planetaria actual no es diferente de estos episodios anteriores. Sí y no, y ambas respuestas son motivo para una ecología de la esperanza.

Existen paralelismos instructivos entre la crisis planetaria actual y la crisis del feudalismo. La agricultura feudal, tras siglos de avance de la productividad, se estancó. La gran expansión comercial de la época, que siguió a estas revoluciones agrícolas, creó una "reserva de enfermedades" afroeuroasiáticas que posibilitó pandemias devastadoras (McNeill, 1976). La penetración fiscal del Estado feudal en el campo transformó las luchas campesinas que pasaron de ser asuntos meramente locales a regionales e incluso "nacionales" (Moore, 2003a). Las clases dominantes, mientras tanto, cayeron progresivamente en la decadencia, luchando por capturar una mayor parte del excedente incluso cuando la "economía real" se estancó.Y, por supuesto, el clima cambió. El auge y la florescencia del feudalismo se enredaron con la Anomalía Climática Medieval cuya crisis es inseparable del inicio de la Pequeña Edad de Hielo ${ }^{53}$. Una sociedad de clases que se desarrolla y prospera en una época climática es poco probable que persista en la siguiente.

Pero el capitalismo persistió. Prosperó en las condiciones de la Pequeña Edad de Hielo que habían sumido al Occidente romano y a la Europa feudal en crisis epocales. Esas condiciones de la Pequeña Edad de Hielo se deterioraron aún más en la década de 1550, cuando los observadores

51 Tras la Peste Negra, “el patrón de retirada de las aldeas precarias reveló no sólo una huida desesperada por la infestación de la peste y una búsqueda de pastos más verdes en un sentido ecológico, sino también un repudio desafiante de los peores terratenientes en favor de sus hermanos más adaptables que demostraron estar dispuestos a aligerar las rentas y renunciar a las cuotas más nocivas de la tenencia servil. A escala local, la resistencia podía adoptar muchas formas: huelgas de alquileres; retirada de los servicios de mano de obra; negativa a pagar los derechos de servidumbre o a atender los mandatos señoriales de reparar los edificios en mal estado, las cercas derribadas y las zanjas obstruidas; rechazo de las órdenes de ocupar las tierras vacantes en las antiguas condiciones serviles; e intimidación de los recaudadores de impuestos reales. Este desafío se extendió como un incendio en las últimas décadas del siglo XIV" (Seccombe, 1995).

52 Cursiva añadida por el autor. Existe, por supuesto, una vasta literatura sobre esta edad de oro de los estándares de vida y sobre los factores institucionales, demográficos y de clase que intervinieron en ella, así como los debates controvertidos al respecto. El propio Braudel se inclina por una interpretación demográfica. Para una explicación de la lucha de clases, véase Federici (2004: 76-82)

53 Para una revisión de la historia del clima y la transición de la Anomalía Climática Medieval a la Pequeña Edad de Hielo, véase Brooke (20I4) La literatura científica e histórica sobre esta transición es voluminosa. 
contemporáneos registraron una serie de inviernos desfavorables. Fue el comienzo del largo y frío siglo XVII, el peor tramo de "mal clima" de la Pequeña Edad de Hielo. Al igual que los momentos anteriores de cambio climático, la Antigüedad y el feudalismo tardíos fueron épocas de guerras interminables, revueltas sociales y crisis económicas. Los genocidios del Nuevo Mundo, al devastar a las poblaciones indígenas, provocaron una disminución sin precedentes del dióxido de carbono atmosférico, a medida que los bosques avanzaban y los suelos quedaban sin alterar por la agricultura. Fue el pico de Orbis (1610), el primer episodio de cambio climático capitalogénico que amplificó los cambios contemporáneos en la Oscilación del Atlántico Norte, la intensidad solar y el vulcanismo. El pico de Orbis contribuyó así al frío severo de la era - y a su volatilidad social y política sin precedentes-. El capitalismo tal y como lo conocemos podría haberse detenido en seco.

Esto no era impensable. De hecho, era el resultado más probable. Desde el punto de vista de los cuatro milenios anteriores, los cambios climáticos y las crisis de clase estaban estrechamente vinculados. Las crisis del Occidente romano en el largo siglo $V$ y de la Europa feudal en el largo siglo XIV señalan la íntima dialéctica entre clima, clase y gobierno. También podemos incluir la crisis de la Edad de Bronce en el siglo XII a.C., durante la cual se produjeron migraciones, guerras y revueltas populares en medio de la sequía y el hambre (Kaniewski et al., 20 I3; Kaniewski et al., 2019).

La forma en que la ecología-mundo capitalista sobrevivió a condiciones climáticas aproximadamente comparables a las anteriores crisis del Occidente romano y del feudalismo es de gran importancia para la política climática actual. El capitalismo sobrevivió a través de tres grandes revoluciones, cada una de las cuales giró en torno a la Gran Frontera y contribuyó al surgimiento del Proletariado Planetario. Estas tres revoluciones fueron el núcleo de una solución climática a la larga crisis climática del siglo XVII, exacerbada, como hemos visto, por el forzamiento capitalógeno del pico de Orbis. Una de ellas fue la revolución militar en marcha desde finales del siglo XV y que alcanzó un punto de inflexión después de 1550 (Parker, 1976; Patel y Moore, 2017). Los ejércitos se hicieron más grandes, más intensivos en capital y más letales, ciertamente en lo referente a su magnitud, al coste y a la fuerza de trabajo. Los nuevos ejércitos eran a la vez motores de la proletarización y palancas de la acumulación impulsada por la deuda, ya que los reyes pedían dinero prestado para financiar sus guerras, lo que les impulsaba a favorecer un giro productivista en toda América. En ningún lugar fueron más evidentes estas contradicciones que en las nuevas colonias, donde las posibilidades de apropiación de la Naturaleza Barata y el poder de los Proyectos Civilizadores eran mayores. En las colonias, "el desarrollo de las fuerzas productivas... procede muy rápidamente" (Marx y Engels, 1976, pp. 82-83). Como hemos visto, toda gran industrialización se apoya en el desarrollo de las "fuerzas productivas" — pivotando sobre la lógica de la acumulación por apropiación- que surgen a través de la Gran Frontera. Fue precisamente el establecimiento político por medios militares de las condiciones de apropiación, y por tanto de superexplotación, lo que más directamente permitió la formación del Proletariado Planetario. Esto supuso un conjunto de formaciones de clase interrelacionadas. Éstas comprendían no sólo el cercamiento y la apropiación de la vida y la fertilidad extrahumanas — la biotarianización — sino la creación de los requisitos de trabajo humano (incluida la fertilidad) necesarios para la rápida acumulación: Proletarización y Femitarización. 
Una segunda revolución fue la Gran Domesticación, que formó el Femitariado. La mitad del siglo XVI marca, como demuestra Federici (2004), un punto de inflexión epocal en la estructura de clase y de género del capitalismo temprano. No es ningún secreto que el declive climático y el recrudecimiento de la "caza de brujas" estuvieran estrechamente relacionados (Oster, 2004). La subordinación de la mujer —formada a través de la abstracción dominante de la Naturaleza que hizo de las mujeres las "salvajes de Europa"- fue una lucha de clases. La redefinición del trabajo de la mujer como "natural" y, por tanto, no social (es decir, sin necesidad de remuneración) fue fundamental para la gran ola de proletarización de los dos siglos siguientes. La Gran Domesticación superexplotativa hizo posible la Gran Proletarización. Los campesinos europeos se convirtieron en trabajadores al menos dos veces y media más rápido que el crecimiento de la población entre 1550 y 1750 (Tilly, I983).

En las Américas - el corazón de la frontera de las mercancías de principios de la modernidad- las burguesías imperialistas forjaron una de las revoluciones productivistas más audaces de la historia de la humanidad. Podemos llamarla "la Revolución de la Plantación" por lo indispensables que fueron sus procesos extractivos, manufactureros y ganaderos ${ }^{54}$. Su eje histórico-mundial fue la plantación de azúcar. En una rápida secuencia de movimientos fronterizos — que comenzó en Brasil durante la década de 1560 - las riquezas del Rey Azúcar engrasaron las ruedas de la acumulación mundial en el siglo XVII y, en el siguiente, proporcionaron los incrementos cruciales de formación de capital para la Revolución Industrial (Blackburn, 1998, pp. 5 I I-580). El racismo y el sexismo intensificaron, de la manera más brutal, el "segundo turno" de la mujer esclava (Morgan, 2004). El prometeísmo impuso una lógica similar al Biotariado, de hecho, el agotamiento asesino de la tierra y el proletariado de las plantaciones estaban íntimamente ligados en las fronteras de las plantaciones (Moore, 2000c). La cristalización de la revolución de las plantaciones en la división de clases y el apartheid climático proporcionaría, a su vez, el aparato esencial de poder y beneficio para la combinación de tecno-recursos fundamentales para la revolución industrial dependiente del algodón y la desmotadora de algodón en un régimen de trabajo superexplotado (Moore, 2017a) y no del carbón y la máquina de vapor. Manchester se «levantó» sobre las clases trabajadoras superexplotadas del Delta del Mississippi (Moore, 2010c y 2010d). Tampoco fue una coincidencia que el Rey Algodón apareciera en escena durante la última gran ola de frío de la Pequeña Edad de Hielo, como lo había hecho el Rey Azúcar dos siglos antes. En conjunto, esta época marcó el nacimiento de la trinidad capitalógena: la división de clases, el apartheid y el patriarcado climáticos.

La burguesía mundial actual no está exenta de este patrón. De hecho, el impulso hacia la superexplotación característico de épocas pretéritas se repite (¿como una farsa?) en el actual resurgimiento del etnonacionalismo y la militarización de las fronteras. Pero no basta con reafirmar las verdades eurocéntricas de la lucha de clases, ni combinarlas con las nociones reificadas de raza, o de combustibles fósiles, o de residuos, o de crecimiento. Para dar sentido al Capitaloceno necesitaremos conceptualizar y mapear estas y otras dinámicas en lo que Marx y Engels (1976, p. 49) llaman el "movimiento real" de sus relaciones "histórico-mundiales". Lo fundamental es una dialéctica de múltiples capas, en la que dos momentos ocupan un lugar destacado. Uno es la conexión entre las ideologías opresoras fundamentales del capitalismo, las prácticas que permiten, la interminable acumulación de capital y la formación del Proletariado Planetario. El racismo,

54 Esta denominación proviene de Sheridan (1969). 
el sexismo y el prometeísmo han sido fundamentales para el ADN del capitalismo porque -en sus sucesivas reinvenciones desde 1492 - han favorecido la tasa de ganancia y facilitado la tendencia a la sobreacumulación. Otra es la conexión entre el capitalismo como proyecto y proceso ecohistórico de las redes de vida que incluye la sociedad de clases y la lucha de clases. La Gran Frontera, su surgimiento y su actual desaparición, ha sido fundamental para ambos.

¿Qué camino seguir? El carácter distintivo de la crisis climática del siglo XXI no se limita a la magnitud del momento geofísico, sino que también se encuentra en la no linealidad del cambio geohistórico. Se trata de la transición de la Gran Frontera al Gran Estancamiento y la Gran Implosión, una dinámica no sólo de estancamiento económico y técnico, y no sólo de inestabilidad geofísica, sino también de intensificación de la lucha de clases. Ciertamente, desde la década de 1970, la lucha de clases mundial ha favorecido a las burguesías imperialistas. La no aparición de una nueva revolución que promueva la productividad en medio de la Gran Implosión ha hecho que el capitalismo sea vulnerable a una poderosa crítica. Esa crítica subraya el carácter rentista y depredador del capitalismo tardío, rompiendo con la dialéctica de "productividad-sumisión" del capitalismo de siempre (Sassen, 20I4; Klein, 2008; Harvey, 2005). Esto marca una "importante inversión de la estrategia de las clases privilegiadas... un retorno a la estrategia anterior a 1848 de manejar el descontento de los trabajadores mediante la indiferencia y la represión". Después de 1848 y hasta 1968, aproximadamente, las clases privilegiadas intentaron apaciguar a las clases trabajadoras mediante la institución de un estado liberal combinado con dosis de concesiones económicas". Por supuesto, esas "concesiones económicas" (Wallerstein, 1995, p. 26), por limitadas que fueran, lo debían todo a las sucesivas industrializaciones que aumentaban la productividad, $y$, en el siglo XX, al espectro del comunismo "realmente existente". Hoy en día esa inversión histórica se manifiesta en una fuerte intensificación de la vigilancia y de las formas militarizadas de disciplina social y geográfica. También se expresa en el agotamiento de la imaginación de la burguesía, sobre todo en el agotamiento de su capacidad para frenar el calentamiento global desbocado. Su contratendencia histórica-mundial se encuentra enterrada en lo más profundo de los orígenes del capitalismo y de la Gran Frontera: la tendencia a la Proletarización Planetaria como el "todo orgánico" del Proletariado-Biotariado-Femitariado. En esta alternativa, la Cuestión de la Biosfera se convierte en una cuestión de transformación revolucionaria, no de gestión planetaria ${ }^{55}$.

La crisis planetaria de hoy es, por tanto, diferente en el grado de interdependencia alcanzado a través del impulso histórico-mundial del capitalismo para colonizar la vida cotidiana al servicio de la acumulación de capital. Esto implica, como hemos visto, Proyectos Civilizadores, dinámicas de clase y estrategias de Naturaleza Barata de todo tipo como "premisa práctica absolutamente necesaria" (Marx y Engels, 1976, p. 49). El doble registro de la Naturaleza Barata — de valorización y devaluación - crea las condiciones para la "existencia empírica de los hombres en su ser histórico-mundial, en lugar de local” (Marx y Engels, 1976, p. 49). Esta transformación sin precedentes - permitida por la dinámica de clase espacializada de la Gran Frontera- marcó el triunfo epocal de la burguesía mundial y la derrota (temporal) del proletariado mundial, que "se esclaviza cada vez más bajo un poder que le es ajeno"(Marx y Engels, 1976, p. 5I). Sin embargo, cuanto más transforma el capitalismo las fuerzas de producción en "hechos histórico-mundiales" - y seguramente esto debe incluir el impulso prometeico de convertir la Naturaleza en una fuente de trabajo no remunerado (biotarianización)—, más establece las posibilidades del "co-

55 Sobre el gerencialismo planetario, véase Fernando Elichirigoity (1999). 
munismo" como "movimiento histórico-mundial... que suprima el actual estado de cosas"(Marx y Engels, 1976, p. 5 I). Marx y Engels no están diciendo que esto sea inevitable — de hecho, tal hegelianismo precisamente va en contra de lo que estaban argumentando-. Por el contrario, plantean la tendencia mundial a la destrucción del "suelo y del trabajador" y la contratendencia hacia su (necesaria) mutua emancipación dentro de la historicidad-mundial del capitalismo.

Lo que he llamado "la revuelta del Biotariado" es, desde este punto de vista, una relación interna del capitalismo y su dinámica de clase — parte del movimiento histórico-mundial que Marx llama comunismo-. Prefigura la Justicia Planetaria como la política del Proletariado Planetario. Por supuesto que se trata de una tendencia en el "sentido hegeliano de lo 'abstracto'", constituida a través de sus contratendencias (Sweezy, 1968, p. 19).Y, por supuesto que se trata de una unidad diferenciada. No es necesario -ipuedo oír las objeciones incluso mientras escribo estas palabras! - plantear un aplanamiento del Biotariado, Femitariado y Proletariado. De hecho, desde una perspectiva dialéctica tal aplanamiento es anatema. La revolución proletaria abstraída de una lucha continua para abolir la relación biotariana -la alienación, fragmentación y disciplinamiento centrado en el trabajo del "resto de la naturaleza" - es una receta para la necrosis planetaria.Y como las feministas socialistas han argumentado durante más de un siglo, la emancipación de la clase trabajadora no puede abstraerse de las dinámicas de opresión y apropiación en las diversas zonas de reproducción social, donde se encuentra el nexo feminista.

En lugar de los “límites del crecimiento", la ecología-mundo ofrece una alternativa: no sólo es posible "Otro mundo" —el eslogan no oficial de la Forma Social Mundial— sino: otra lucha de clases es posible. En el Gran Estancamiento ya ha comenzado la revuelta del Biotariado — cuya contribución a la desestabilización revolucionaria del capitalismo ha sido subestimada tanto por los ecologistas como por los marxistas-. Con demasiada frecuencia, la izquierda ha visto las redes de la vida desde el punto de vista del gestor de los planos, en lugar de percibirlos como compañeros en la lucha por la justicia planetaria —-por el Socialismo Biotariano contra la dictadura biosférica del capital-. Aunque es fácil romantizarlo, captar la red de la vida a través del oikeios, el pulso creativo, generativo y multicapa de la creación de vida, nos pide que reexaminemos la solidaridad humana con el resto de la naturaleza de forma que desafíe la dominación prometeica de la vida y que explore las posibilidades comunistas de liberación: "también las criaturas deben ser libres" (Müntzer citado por Marx en Tucker, 1978, p.5 I). Poniendo en primer plano las dinámicas opresivas y explotadoras del trabajo, la vida y el poder, la Justicia Planetaria da prioridad a la abolición de la relación Proletaria-Biotaria-Femitaria creada a través de la Gran Frontera después de 1492. Este es el reto de la lucha de clases planetaria en los últimos días del Holoceno - y los primeros días de la Gran Implosión-.

\section{Referencias}

Alatas, H. (1977). The Myth of the Lazy Native:A Study of the Image of the Malays, Filipinos and Javanese from the I6th to the 20th Century and Its Function in the Ideology of Colonial Capitalism. Londres: Psychology Press.

Amin, S. (2012). The Surplus in Monopoly Capitalism and the Imperialist Rent. Monthly Review, 64(3), 78-83.

Andersen, M. A., Alston, J. M., Pardey, P. G., \& Smith, A. (2018). A Century of U.S. Farm Productivity Growth:A Surge Then a Slowdown. American Journal of Agricultural Economics, I00(4), 1072-1090. https://doi.org/I0.1093/ajae/ aay023

Araghi, F. (2009).Accumulation by Displacement: Global Enclosures, Food Crisis, and the Ecological Contradictions of Capitalism. Review (Fernand Braudel Center), 32(I), I I3-I46. 
Arrighi, G. (2010). The Long Twentieth Century: Money, Power and the Origins of Our Times. Nueva York:Verso Books. Banaji, J. (20I I). Theory As History: Essays On Modes Of Production And Exploitation: Historical Materialism. Leiden: Brill. Baran, P.A., \& Sweezy, P. M. (1966). Monopoly Capital. Nueva York: Monthly Review Press.

Barbier, E. B. (20I5). Nature andWealth. Overcoming Environmental Scarcity and Inequality. Nueva York: Palgrave Macmillan. Barca, S. (2020). Forces of Reproduction. Cambridge: Cambridge University Press.

Barnosky, A. D., Hadly, E.A., Bascompte, J., Berlow, E. L., Brown, J. H., Fortelius, M., ... Smith, A. B. (20I2).Approaching a state shift in Earth's biosphere. Nature, 486(740 I), 52-58. https://doi.org/10.1038/nature I I 018

Bellamy Foster, J. ( I 989).Age of Restructuring. In Instability and Change in the World Economy (pp. 28I-297). Nueva York: Monthly Review Press.

Bellamy Foster, J. (20I3). The Ecological Revolution: Making Peace with the Planet. Nueva York: Monthly Review Press.

Bellamy Foster, J., \& Yates, M. D. (20I4). Piketty and the crisis of neoclassical economics. Monthly Review, 66(6), I-24.

Benanav, A. (2019). Automation and the Future of Work - I. New Left Review, I I 9(II), 5-38.

Betancor, O. (2017). The Matter of Empire: Metaphysics and Mining in Colonial Peru. Pittsburgh: University of Pittsburgh Press.

Blackburn, R. (1998). The Making of New World Slavery. Londres:Verso Books.

Bond, P. (2007). Introduction: two economies - or one system of superexploitation. Africanus, 37, I-2I .

Braconnier, H., Nicoletti, G., \& Wetsmore, B. (20I4). Policy Challenges For the Next 50 Years. Paris.

Braudel, F. (198I). Structures of Everyday Life (Civilization and Capitalism, I5th-I 8th Century). Nueva York: Harper Collins Publisher.

Braverman, H. (1975). Labor and Monopoly Capital:The Degradation ofWork in the Twentieth Century. Nueva York: Monthly Review Press.

Brenner, N. (2019). New Urban Spaces: Urban Theory and the Scale Question. Oxford: Oxford University Press.

Brenner, N., \& Katsikis, N. (2020). Operational Landscapes: Hinterlands of the Capitalocene. Architectural Design, 90(I), 22-3I. https://doi.org/https://doi.org/10.1002/ad.252

Brenner, R. (1976). Agrarian class structure and economic development in pre-industrial Europe. Past \& Present, 70 , $30-75$

Brenner, R. (1977). The origins of capitalist development: a critique of neo-Smithian Marxism. New Left Review, I04, 25-92.

Brooke, J. L. (20I4). Climate Change and the Course of Global History:A Rough Journey. Cambridge: Cambridge University Press.

Burckhardt, J. (1979). Reflections on History. Indianapolis: Liberty Fund Inc.

Cameron, C. M., Kelton, P., \& Swedlund,A. (2016). Beyond Germs: Native Depopulation in North America.Tucson:University of Arizona Press.

Carchedi, G., \& Roberts, M. (20I3). The Long Roots of the Present Crisis: Keynesians, Austerians, and Marx's Law. World Review of Political Economy, 4(I), 86-II5.

Chiilde,V. G. (195I). Man Makes Himself. Nueva York: New American Library.

Christophers, B. (2020). Rentier Capitalism: Who Owns the Economy, and Who Pays for It? Londres:Verso Books.

Midnight Notes Collective (2009). Promissory Notes: From Crisis to Commons.

Collis, S. (2016). Once in Blockadia.Vancouver:Talon Books.

Cowen, T. (20I I). The Great Stagnation: How America Ate All The Low-Hanging Fruit of Modern History, Got Sick, and Will (Eventually) Feel Better. Boston: Dutton.

De Loughry, T. (2019). Polymeric chains and petrolic imaginaries: world literature, plastic, and negative value. Green Letters, 23(2), I79-193. https://doi.org/I0.1080/|46884 I7.2019.165066 I

De Ste Croix, G. E. M. (198I). Class Struggle in the Ancient Greek World: From the Archaic Age to the Arab Conquests. Ithaca: Cornell University Press.

Diamond, J. (2005). Collapse: How Societies Choose to Fail or Succeed. Nueva York:Viking.

Drake, B. L. (2017). Changes in North Atlantic Oscillation drove Population Migrations and the Collapse of the Western Roman Empire. Scientific Reports, 7(I), I227. https://doi.org/I0.1038/s4I598-017-01289-z

Du Bois,W. E. B. (1999). Black Reconstruction in America 1860- I880. Nueva York: Free Press.

Elichirigoity, F. (1999). Planet Management: Limits to Growth, Computer Simulation, and the Emergence of Global Spaces. Evanston: Northwestern University Press.

Escobar, A. (20II). Encountering Development: The Making and Unmaking of the Third World. Princeton: Princeton University Press.

Eurostat. (2019). Agricultural labour productivity on the rise again. Luxemburgo.

Federici, S. (2004). Caliban And The Witch:Women, The Body, and Primitive Accumulation. Nueva York:Autonomedia.

Fick, C. (2000). Emancipation in Haiti: From plantation labour to peasant proprietorship. Slavery \& Abolition, 2 I (2), I I 40. https://doi.org/ I0.1080/0 I440390008575304

Fuglie, K. O., MacDonald, J. M., \& Ball, E. (2007). Productivity Growth in U.S. Agriculture.Washington D.C.

Gadgil, M., \& Guha, R. (1994). This Fissured Land:An Ecological History of India. Oxford: Oxford Paperbacks.

Gaffney, M., Ravenscroft, C., \&Williams, C. (2020). Capitalism and planetary justice in the web of life:An Interview with Jason W. Moore. Polygraph, 28, I6I-182.

Genovese, E. (198I). From Rebellion to Revolution:Afro-American Slave Revolts in the Making of the Modern World. Baton Rouge: Louisiana State University Press. 
Goldstein, J. (2018). Planetary Improvement: Cleantech Entrepreneurship and the Contradictions of Green Capitalism. Cambridge:The MIT Press.

Gordon, R. J. (2016). The Rise and Fall of American Growth: The U.S. Standard of Living since the Civil War. Princeton: Princeton University Press.

Graham, J. (2017). “A country with land but no habitat”: Women, violent accumulation and negative-value in Yvonne Vera's The Stone Virgins. Journal of Postcolonial Writing, 53(3), 355-366. https://doi.org/ I0.1080/I 7449855.20 I 7.1337689

Hage, G. (2017). Is Racism an Environmental Threat? (Debating Race). Cambridge: Polity Press.

Halsall, G. (2007). Barbarian Migrations and the Roman West, 376-568. Cambridge: Cambridge University Press.

Harper, K. (2016). Slavery in the Late Roman World,AD 275-425. Cambridge: Cambridge University Press.

Harper, K. (2017). The Fate of Rome: Climate, Disease, and the End of an Empire. Princeton: Princeton University Press.

Harvey, D. (199I). The Condition of Postmodernity: An Enquiry into the Origins of Cultural Change. Hoboken: Blackwell Publishers.

Harvey, D. (1998). What's green and makes the environment go round? In F. Jameson \& M. Miyoshi (Eds.), The Cultures of Globalization (pp. 327-355). Raleigh: Duke University Press.

Harvey, D. (2005). The New Imperialism. Oxford: Oxford University Press.

Harvey, D. (2018). Abstract from the concrete: Capitalism spiralling out of control. In A.Andreotti \& D. Benassi (Eds.), Western Capitalism in Transition (pp. 45-60). Manchester: Manchester University Press.

Hilton, R. H. (195I).Y eut-il une crise générale de la féodalité ? Annales. Histoire, Sciences Sociales, 6(I), 23-30. https:// doi.org/DOI: 10.3406/ahess. 195I.1903

Hilton, R. (20I0). The Transition from Feudalism to Capitalism. Nueva Delhi:Aakar Books.

Hixson,W. (20I3). American Settler Colonialism A History. Nueva York: Palgrave Macmillan.

Holt, D. H. (20I I). Germania and Climate Variability in 3rd and 4th Centuries A.D.: A Methodological Approach to Dendroclimatology and Human Migration. Physical Geography, 32(3), 24I-268. https://doi.org/ 0.2747/02723646.32.3.24I

Huntington, S. P. (1993). The Clash of Civilizations? Foreign Affairs, 72(3), 22-49.

Innes, M. (2007). Introduction to Early Medieval Western Europe, 300-900:The Sword, the Plough and the Book. Londres: Routledge.

James, C. L. R. (1989). The Black Jacobins: Toussaint L'Ouverture and the San Domingo Revolution. Nueva York: Vintage Books.

Jeanne Fields, B. (1990). Slavery, race and ideology in the United States of America. New Left Review, I8I (I), 95-I I8.

Johnson,W. (2004). The Pedestal and the Veil: Rethinking the Capitalism/Slavery Question.Journal of the Early Republic, 24(2), 299-308.

Jones, D. S. (20I4). Epidemics in Indian Country. In Oxford Research Encyclopedia of American History. Oxford: Oxford University Press.

Kaniewski, D., Marriner, N., Bretschneider, J., Jans, G., Morhange, C., Cheddadi, R., ... Van Campo, E. (2019). 300-year drought frames Late Bronze Age to Early Iron Age transition in the Near East: new palaeoecological data from Cyprus and Syria. Regional Environmental Change, 19(8), 2287-2297. https://doi.org/10.1007/s I0I I3-018$01460-w$

Kaniewski, D., Van Campo, E., Guiot, J., Le Burel, S., Otto, T., \& Baeteman, C. (20I3). Environmental roots of the Late Bronze Age crisis. PLoS ONE, 8(8), I- 10.

Katsikis, N. (2016). From Hinterland to Hinterglobe: Urbanization as Geographical Organization. Harvard University.

Klein, N. (2008). The Shock Doctrine:The Rise of Disaster Capitalism. Nueva York: Macmillan USA.

Koepke, N., \& Baten, J. (2008). Agricultural specialization and height in ancient and medieval Europe. Explorations in Economic History, 45(2), I27-I46. https://doi.org/ I0.1016/j.eeh.2007.09.003

Latour, B. (2018). Down to Earth: Politics in the New Climatic Regime. Cambridge: Polity Press.

Le Roy Ladurie, E., \& Daux,V. (2008). The climate in Burgundy and elsewhere, from the fourteenth to the twentieth century. Interdisciplinary Science Reviews, 33(I), I0-24. https://doi.org/ I0.1 I 79/03080 I808X2600I 3

Lenin, V. I. (1963). Imperialism, the Highest Stage of Capitalism A Popular Outline. Moscú: Progress Publishers.

Lenin, V. I. (I 964). The Development of Capitalism in Russia. (P. Publishers, Ed.). Moscú.

Lewis, S. L., \& Maslin, M. A. (2015). Defining the Anthropocene. Nature, 5 /9(7542), I7I-I80. https://doi.org/I0.1038/ nature 14258

Lewit, T. (2005). Bones in the Bathhouse: Re-evaluating the Notion of "Squatter Occupation" in 5th-7th CenturyVillas. In G. Pietro Brogiolo, A. Chavarría Arnau, \& M.Valenti (Eds.), Dopo la fine delle ville: le campagne dal VI al IX secolo (pp. 25I-262). Mantova: Società Archeologica.

Lewit, T. (2009). Pigs, presses and pastoralism: farming in the fifth to sixth centuries AD. Early Medieval Europe, I 7(I), 77-9I. https://doi.org/ I0. II I I/j. I468-0254.2009.00245.x

Lewontin, R., \& Levins, R. ( 1997). Organism and environment. Capitalism Nature Socialism, 8(2), 95-98.

Liang, X.-Z., Wu, Y., Chambers, R. G., Schmoldt, D. L., Gao, W., Liu, C., ... Kennedy, J. A. (2017). Determining climate effects on US total agricultural productivity. Proceedings of the National Academy of Sciences, I I 4( I 2 ), E2285 LP-E2292. https://doi.org/I0.1073/pnas. I615922II4

Linebaugh, P., \& Rediker, M. (2013). The Many-Headed Hydra: Sailors, Slaves, Commoners, and the Hidden History of the Revolutionary Atlantic. Boston: Beacon Press. 
Lobell, D. B., Schlenker,W., \& Costa-Roberts, J. (20I I). Climate Trends and Global Crop Production Since 1980. Science, 333(6042), 616 LP - 620. https://doi.org// 0.I I 26/science. I 20453 I

Lotta, R. (1985). The Political Economy of Apartheid and the Strategic Stakes of Imperialism. Race \& Class, 27(2), I7-34.

Löwy, M. (20I5). Ecosocialism:A Radical Alternative to Capitalist Catastrophe. Chicago: Haymarket Books.

Magdoff, H. (1989). Imperialism: From the colonial age to the present. Nueva York: Monthly Review Press.

Maito, E. E. (2018). The Tendency of the Rate of Profit to Fall since the Nineteenth. Century and a World Rate of Profit. In G. Carchedi \& M. Roberts (Eds.), World in Crisis:A Global Analysis of Marx’s Law of Profitability (pp. I40-I67). Chicago: Haymarket Books.

Malm,A. (20I6). Fossil Capital:The Rise of Steam-Power and the Roots of Global Warming. Nueva York:Verso Books.

Mamdani, M. (2012). Define and Rule: Native as Political Identity. Cambridge: Harvard University Press.

Mandel, E. (1999). Late Capitalism. Londres:Verso Books.

Mann, M. E. (2002). Little Ice Age. In M. C. MacCracken \& J. S. Perry (Eds.), Encyclopedia of Global Environmental Change, Vol. I:The Earth system: physical and chemical dimensions of global environmental change (pp. 504-509). Nueva York: John Wiley \& Sons.

Marley, B.J. (2016). The Coal Crisis in Appalachia:Agrarian Transformation, Commodity Frontiers and the Geographies of Capital. Journal of Agrarian Change, I 6(2), 225-254. https://doi.org/ I 0. I I I I/joac. I 2 I 04

Marx, K. ( I 967). El Capital, Vol. I. Nueva York: International Publishers.

Marx, K. (1973). Foundations of the Critique of Political Economy.Vol.3 (Grundrisse) 1857-I 858. Londres: Penguin Books.

Marx, K., \& Engels, F. (1976). Collected Works Vol.5. Nueva York: International Publishers.

McBrien,J.(2016).Accumulating extinction:Planetary Catastrophism in the Necrocene.In J.W. Moore (Ed.),Antropocene or Capitalocene? Nature, History, and the crisis of Capitalism (pp. I I6- I37). Oakland: PM Press.

McCormick, M., Büntgen, U., Cane, M.A., Cook, E. R., Harper, K., Huybers, P., ... Tegel,W. (20I2). Climate Change during and after the Roman Empire: Reconstructing the Past from Scientific and Historical Evidence. The Journal of Interdisciplinary History, 43(2), 169-220.

McMichael, P. (1 984). Settlers and the agrarian question: Capitalism in Colonial Australia. Cambridge: Cambridge University Press.

McNally, R. (1993). Against the Market: Political Economy, Market Socialism and the Marxist Critique. Nueva York: Verso Books.

McNeill,W. H. (1976). Plagues and Peoples. Garden City: Doubleday.

Miller, Joseph, C. (1997). Way of Death:Merchant Capitalism and the Angolan Slave Trade, I 730-I 830.Wisconsin:University of Wisconsin Press.

Mintz, S.W. (1978).Was the Plantation Slave a Proletarian? Review (Fernand Braudel Center), 2(I), 8I-98.

Moore, J.W. (2000a). Environmental Crises and the Metabolic Rift in World-Historical Perspective. Organization \& Environment, I3(2), I23-I57. https://doi.org//0.1 I77/I086026600 I3200 I

Moore, J.W. (2000b). Marx and the Historical Ecology of Capital Accumulation on a World Scale:A Comment on Alf Hornborg's "Ecosystems and World Systems:Accumulation as an Ecological Process. Journal of World-Systems Research, 6(I SE-General Section), I33- I 38. https://doi.org/I0.5/95/jwsr.2000.234

Moore, J.W. (2000c). Sugar and the Expansion of the Early Modern World-Economy: Commodity Frontiers, Ecological Transformation, and Industrialization. Review (Fernand Braudel Center), 23(3), 409-433.

Moore, J.W. (200I). Marx's Ecology and the Environmental History of World Capitalism. Capitalism Nature Socialism, I 2(3), I34- I39. https://doi.org/ I 0. I080/ I0455750 I I 0 I 245045

Moore, J.W. (2002). The crisis of feudalism:An Environmental History. Organization \& Environment, I5(3), 30 I-322.

Moore, J.W. (2003a). Nature and the Transition from Feudalism to Capitalism. Review (Fernand Braudel Center), 26(2), $97-172$.

Moore, J.W. (2003b). Capitalism as World-Ecology: Braudel and Marx on Environmental History. Organization \& Environment, I6(4), 43I-458.

Moore, J.W. (2003c). "The Modern World-System" as Environmental History? Ecology and the Rise of Capitalism. Theory and Society, 32(3), 307-377.

Moore, J.W. (2003d). Ecology and Imperialism. Monthly Review, 55(2), 58-62.

Moore, J.W. (2004a). Conceptualizing World Environmental History: The Contribution of Immanuel Wallerstein. In G. Backhouse \& J. Murungi (Eds.), Earth Ways: Framing Geographical Meanings (pp. 23-42). Londres: Lexington Books.

Moore, J.W. (2004b). Metabolic Rifts, East and West? Socio-Ecological Crises, from the Rise of the West to the Resurgence of East Asia (PEWS News: Newsletter of the Political Economy of the World-System Section). Washington D.C.

Moore, J.W. (2007a). Ecology and the Rise of Capitalism. University of California, Berkeley.

Moore, J.W. (2007b). Silver, Ecology, and the Origins of the Modern World, I450- I64. In J. R. McNeill, J. Martinez-Alier \& A. Hornborg (Eds.), Environmental History:World System History and Global Environmental Change (pp. I23142). Lanham:AltaMira Press.

Moore, J.W. (2008). Ecological Crises and the Agrarian Question in World-Historical Perspective. Monthly Review, 60(6), 54-63

Moore, J.W. (2009). Madeira, Sugar, and the Conquest of Nature in the "First" Sixteenth Century: Part I: From "Island of Timber" to Sugar Revolution, I420\&\#x2013;1506. Review (Fernand Braudel Center), 32(4), 345-390.

Moore, J.W. (2010a). "This lofty mountain of silver could conquer the whole world”: Potosí and the political ecology 
of underdevelopment, I545-I800. The Journal of Philosophical Economics, 4(I), 58-103.

Moore, J.W. (20I0b). The End of the Road? Agricultural Revolutions in the Capitalist World-Ecology, I450-20I0. Journal of Agrarian Change, I0(3), 389-4I3. https://doi.org/I0.I I I I/j. I47I-0366.2010.00276.x

Moore, J.W. (2010c). 'Amsterdam is Standing on Norway' Part I: The Alchemy of Capital, Empire and Nature in the Diaspora of Silver, I545-1648. Journal of Agrarian Change, I0(I), 33-68. https://doi.org/I0.III I/j. I47 I 0366.2009.00256.x

Moore,J.W.(2010d). 'Amsterdam is Standing on Norway' Part II:The Global North Atlantic in the Ecological Revolution of the Long Seventeenth Century. Journal of Agrarian Change, I0(2), I88-227. https://doi.org/I0.I I I //j. I47 I 0366.2009.00262.x

Moore, J.W. (2010e). Madeira, Sugar, and the Conquest of Nature in the "First" Sixteenth Century, Part II: From Regional Crisis to Commodity Frontier, I506\&\#x2014;1530. Review (Fernand Braudel Center), 33(I), I-24.

Moore, J.W. (2010f). Cheap Food \& Bad Money: Food, Frontiers, and Financialization in the Rise and Demise of Neoliberalism. Review (Fernand Braudel Center), 33(2/3), 225-26I.

Moore, J.W. (20I la). Ecology, Capital, and the Nature of Our Times: Accumulation; Crisis in the Capitalist WorldEcology. Journal of World-Systems Research, I 7(I SE-The World-Historical Imagination: Giovanni Arrighi's The Long Twentieth Century in Prospect and Retrospect), I07-I46. https://doi.org/ I0.5 I95/jwsr.20I I.432

Moore, J.W. (20l Ib). Transcending the metabolic rift: a theory of crises in the capitalist world-ecology. The Journal of Peasant Studies, 38(I), I-46. https://doi.org/I0.1080/03066I50.2010.538579

Moore, J.W. (20I4). The Value of Everything? Work, Capital, and Historical Nature in the Capitalist World-Ecology. Review (Fernand Braudel Center), 37(3-4), 245-292

Moore, J.W. (2015a). Capitalism in the Web of Life: Ecology and the Accumulation of Capital. Nueva York:Verso.

Moore, J.W. (20I5b). Putting Nature to Work:Anthropocene, Capitalocene, and the Challenge of World-Ecology. In C. Wee \& O.Arndt (Eds.), Supramarkt:A micro-toolkit for disobedient consumers, or how to frack the fatal forces of the Capitalocene (pp. 69-II7). Gotemburgo: Irene Books.

Moore, J.W. (2015c). Nature in the limits to capital (and vice versa). Radical Philosophy, 193, 9-19.

Moore, J.W. (2015d). Cheap Food and Bad Climate: From Surplus Value to Negative Value in the Capitalist WorldEcology. Critical Historical Studies, 2(I), I-43. https://doi.org/I0.1086/68I007

Moore, J.W. (20I7a).World accumulation and planetary life, or, why capitalism will not survive until the 'last tree is cut.' IPPR Progressive Review, 24(3), I76-202.

Moore, J.W. (20I7b). Metabolic rift or metabolic shift? dialectics, nature, and the world-historical method. Theory and Society, 46(4), 285-3 I8. https://doi.org/I0.1007/s I I I86-017-9290-6

Moore, J.W. (2017c). The Capitalocene, Part I: on the nature and origins of our ecological crisis. The Journal of Peasant Studies, 44(3), 594-630. https://doi.org/10.1080/03066/50.2016.1235036

Moore, J.W. (2017d). Confronting the Popular Anthropocene:Toward an Ecology of Hope. New Geographies, 9, I86191.

Moore, J.W. (20I7e). Anthropocenes \& the Capitalocene Alternative. Azimuth, 5, 7I-80.

Moore, J.W. (2018a). The Capitalocene Part II: accumulation by appropriation and the centrality of unpaid work/ energy. The Journal of Peasant Studies, 45(2), 237-279. https://doi.org/I 0. I080/03066 I 50.20 I6. 1272587

Moore, J.W. (2018b). Slaveship Earth \& the World-Historical Imagination in the Age of Climate Crisis. PEWS News: Newsletter of the Political Economy of the World-System Section. Washington D.C.

Moore, J.W. (2019). The Capitalocene and Planetary Justice. Maize, 6, 49-54.

Morgan, J. (2004). Laboring Women: Reproduction and Gender in New World Slavery. Filadelfia: University of Pennsylvania Press.

Murray, P. (20I3). Marx’s Theory Of Scientific Knowledge. Búfalo: Prometheus Books.

Nading, A. (2019). The Heat of Work: Dissipation, Solidarity, and Kidney Disease in Nicaragua. In S. Besky \& A. Blanchette (Eds.), How Nature Works: Rethinking Labor on a Troubled Planet (pp. 97-I I4). Santa Fe: University of New Mexico Press.

O'Connor, J. (1998). Natural Causes: Essays in Ecological Marxism. Nueva York: Guilford Press.

OIT. (2014). Global Employment Trends 20 14: Risk of a Jobless Recovery? Ginebra.

OIT. (2019). Working on a warmer planet:The impact of heat stress on labour productivity and decent work. Ginebra.

Ortiz-Bobea, A., Ault, T. R., Carrillo, C. M., Chambers, R. G., \& Lobell, D. B. (202I). Anthropogenic climate change has slowed global agricultural productivity growth. Nature Climate Change, I I (4), 306-3 I 2. https://doi.org/ I0. I038/ s4I558-02I-01000-I

Ortiz-Bobea, A., Knippenberg, E., \& Chambers, R. G. (20I8). Growing climatic sensitivity of U.S. agriculture linked to technological change and regional specialization. Science Advances, 4(I2), eaat4343. https://doi.org//0.I I 26/ sciadv.aat4343

Oster, E. (2004). Witchcraft, Weather and Economic Growth in Renaissance Europe. Journal of Economic Perspectives, I8(I), 2I 5-228. https://doi.org/10.1257/089533004773563502

Otero, G., \& Lapegna, P. (2016).Transgenic Crops in Latin America: Expropriation, Negative Value and the State. Journal of Agrarian Change, I 6(4), 665-674. https://doi.org/ I0.1 I I I/joac. 12159

Parenti, C. (2016). Environment-Making in the Capitalocene:The Political Ecology of the State. In J.W. Moore (Ed.), Antropocene or Capitalocene? Nature, History, and the crisis of Capitalism (pp. 166- 183). Oakland: PM Press.

Parenti, C. (2020). Radical Hamilton: Economic Lessons from a Misunderstood Founder. Nueva York:Verso Books. 
Parker, G. (1976). The “Military Revolution,” I 560-I660--a Myth? The Journal of Modern History, 48(2), I 96-2I4.

Parker, G. (2013). Global Crisis:War, Climate Change and Catastrophe in the Seventeenth Century. Londres:Yale University Press.

Patel, R., \& Moore, J.W. (20I7). A History of the World in Seven Cheap Things. A Guide to Capitalism, Nature and the Future of the Planet. Oakland: University of California Press.

Plumwood,V. (1 993). Feminism and the Mastery of Nature. Londres: Routledge.

Richards, J. F. (2006). The Unending Frontier:An Environmental History of the Early Modern World. Berkeley: University of California Press.

Roberts, M. (2016). The Long Depression: Marxism and the Global Crisis of Capitalism. Chicago: Haymarket Books.

Robertson,T. (2012). The Malthusian Moment: Global Population Growth and the Birth of American Environmentalism. New Brunswick: Rutgers University Press.

Robinson, C. J. ( 1984). Black Marxism:The Making of the Black Radical Tradition. Londres: Zed Books.

Ruddiman,W.F.(2005). Plows, Plagues, and Petroleum:How Humans Took Control of Climate.Princeton:Princeton University Press.

Said, E.W. (2000). Clash of Definitions. In E.W. Said (Ed.), Reflections On Exile:And Other Literary And Cultural Essays (pp. 569-592). Cambridge: Harvard University Press.

Sassen, S. (2014). Expulsions: Brutality and Complexity in the Global Economy. Cambridge:The Belknap Press.

Schopf, T. J. M. (1972). Punctuated equilibria: an alternative to phyletic gradualism. In Models in Paleobiology (pp. 82-I I5). San Francisco: Freeman, Cooper \& Co.

Schwartz, S. B. (1985). Sugar plantations in the formation of Brazilian society: Bahia, I550-/835. Cambridge: Cambridge University Press.

Schwartz, S. B. (1992). Slaves, Peasants, and Rebels: Reconsidering Brazilian Slavery. Champaign: University of Illinois Press. Seccombe,W. (1995). A Millennium of Family Change: Feudalism to Capitalism in Northwestern Europe. Londres:Verso.

Sheridan, R. B. (1969). The Plantation Revolution and the Industrial Revolution, I625- I 775. Caribbean Studies, 9(3), 5-25.

Skarstein, R. (20II). Overaccumulation of productive capital or of finance capital? A view from the outskirts of a Marxist debate . Investigación Económica.

Smith, J. (2016). Imperialism in the Twenty-First Century: Globalization, Super-Exploitation, and the Crisis of Capitalism. Nueva York: Monthly Review Press.

Sohn-Rethel,A. (2020). Intellectual and Manual Labour:A Critique of Epistemology. Leiden: Brill.

Spooner, F. C. (1972). The International Economy and Monetary Movements in France, 1493-I 725. Cambridge: Harvard University Press.

Steffen,W., Richardson, K., Rockström, J., Cornell, S. E., Fetzer, I., Bennett, E. M., ... Sörlin, S. (20I 5). Planetary boundaries: Guiding human development on a changing planet. Science, 347(6223), 1259855. https://doi.org//0.1 I26/ science. 1259855

Summers, L. H. (20I6). The age of secular stagnation:What it is and what to do about it. Foreign Affairs, 95(2), 2-9.

Swan, S. H., \& Colino, S. (202I). Count Down: How Our Modern World Is Threatening Sperm Counts, Altering Male and Female Reproductive Development, and Imperiling the Future of the Human Race. Nueva York: Scribner.

Sweezy, P. M. ( 1968). The Theory of Capitalist Development. Nueva York: Monthly Review Press.

Sweezy, P. M., \& Magdoff, H. (1972). Dynamics of U.S.Capitalism. Corporate, Structure, Inflation, Credit, Gold and the Dollar. Nueva York: Monthly Review Press.

Tainter, J. (1990). The Collapse of Complex Societies. Cambridge: Cambridge University Press.

Tawney, R. H. (I94I). The Rise of the Gentry, I558-1640. The Economic History Review, II(I), I-38. https://doi. org/ $10.2307 / 2590708$

Thornton, J. (1998). Africa and Africans in the Making of the Atlantic World, I 400-I800. Cambridge: Cambridge University Press.

Tilly, C. (1983). The demographic origins of the European proletariat (CRSO Working Paper No. 286). Michigan.

Toffler, A. (1 984). Future Shock. Barcelona: Random House.

Tomich, D. (2003). Through the Prism of Slavery: Labor, Capital, and World Economy. Lanham: Rowman \& Littlefield Publishers.

Tucker, R. C. (1978). The Marx-Engels Reader. Nueva York:WW Norton \& Co.

Turner, F.J. (192I). The Frontier in American History. Nueva York: Henry Holt and company.

von Werlhof, C. (1988). On the concept of nature and society in capitalism. In Woman the Last Colony (pp. 96-I I2). Londres: Zed Books.

Wallerstein, I. (1974). The Modern World-System I: Capitalist Agriculture and the origins of the European World-Economy in the Sixteenth Century. New York and London:Academic Press.

Wallerstein, I. (1995). Response: Declining States, Declining Rights? International Labor and Working-Class History, (47), 24-27.

Wallis, V. (2000). Species Questions (Gattungsfragen): Humanity and Nature from Marx to Shiva. Organization \& Environment, 13(4), 500-507. https://doi.org/I0.1 I77/1086026600 I34013

Webb,W. P. (1952). The Great Frontier. Boston: Houghton Mifflin.

Webb,W. P. (1 954). The Great Frontier:A Disappearing Boom. The Georgia Review, 8(I), 17-28.

White, S. (2017). A Cold Welcome:The Little Ice Age and Europe's Encounter with North America. Cambridge: Harvard University Press. 
Wickham, C. (2006). Framing the Early Middle Ages: Europe and the Mediterranean, 400-800. Oxford: Oxford University Press.

Wolford,W. (202I).The Plantationocene:A Lusotropical Contribution to the Theory. Annals of the American Association of Geographers, I- I8. https://doi.org/ I0.1080/24694452.2020.185023 I

Wood, E. M. (2017). The Origin of Capitalism:A Longer View. Nueva York:Verso Books.

Wright, M. (2006). Disposable Women and Other Myths of Global Capitalism. Londres: Routledge.

Zander, K. K., Botzen,W.J.W., Oppermann, E., Kjellstrom,T., \& Garnett, S.T. (2015). Heat stress causes substantial labour productivity loss in Australia. Nature Climate Change, 5(7), 647-65 I. https://doi.org/ 10.1038/nclimate2623 


\section{RELACIONES INTERNACIONALES}

Revista académica cuatrimestral de publicación electrónica

Grupo de Estudios de Relaciones Internacionales (GERI)

Universidad Autónoma de Madrid, España

https://revistas.uam.es/relacionesinternacionales

ISSN 1699 - 3950

f facebook.com/RelacionesInternacionales

3. twitter.com/RRInternacional 